\title{
Influence of Piezoelectric Performance on Nonlinear Dynamic Characteristics of MFC Shells
}

\author{
Xiangying Guo $\mathbb{D}^{1,2}$ Pan Jiang, ${ }^{1,2}$ and Dongxing Cao $\mathbb{D}^{1,2}$ \\ ${ }^{1}$ College of Mechanical Engineering, Beijing University of Technology, Beijing 100124, China \\ ${ }^{2}$ Beijing Key Laboratory of Nonlinear Vibrations and Strength of Mechanical Structures, Beijing 100124, China \\ Correspondence should be addressed to Dongxing Cao; caostar@bjut.edu.cn
}

Received 27 June 2019; Accepted 23 August 2019; Published 9 October 2019

Guest Editor: Viet-Thanh Pham

Copyright $($ C 2019 Xiangying Guo et al. This is an open access article distributed under the Creative Commons Attribution License, which permits unrestricted use, distribution, and reproduction in any medium, provided the original work is properly cited.

Based on the structures of unmanned aerial vehicle (UAV) wings, nonlinear dynamic analysis of macrofiber composite (MFC) laminated shells is presented in this paper. The effects of piezoelectric properties and aerodynamic forces on the dynamic stability of the MFC laminated shell are studied. Firstly, under the flow condition of ideal incompressible fluid, the thin airfoil theory is employed to calculate the effects of the mean camber line to obtain the circulation distribution of the wings in subsonic air flow. The steady aerodynamic lift on UAV wings is derived by using the Kutta-Joukowski lift theory. Then, considering the geometric nonlinearity and piezoelectric properties of the MFC material, the nonlinear dynamic model of the MFC laminated shell is established with Hamilton's principles and the Galerkin method. Next, the effects of electric field, external excitation force, and nonlinear parameters on the stability of the system are studied under $1: 1$ internal resonance and the effects of material parameters on the natural frequency of the structure are also analyzed. Furthermore, the influence of the aerodynamic forces and electric field on the nonlinear dynamic responses of MFC laminated shells is discussed by numerical simulation. The results indicate that the electric field and external excitation have great influence on the structural dynamic responses.

\section{Introduction}

MFC material, which was invented by NASA in 1996, has great application prospect in many engineering structures, especially in aviation and aerospace field. MFC materials are composed of two main parts: rectangular piezoceramic fibers and interdigitated electrodes. The sheet of aligned rectangular piezoceramic fibers is used to improve flexibility and damage tolerance in comparison with the traditional monolithic piezoceramic. Interdigitated electrode patterns are attached to the top and bottom of a polyamide film to permit in-plane poling and actuation of the piezoelectric fibers. MFCs mainly have two different types, namely, $d 31$ and $d 33$ modes, based on different laying directions of the piezoelectric fiber material.

Because of the great potential of piezoelectric composite materials, piezoelectric materials become the most commonly used smart materials in active vibration and noise control, energy harvest, and so on. Tan et al. [1] studied the dynamic characteristics of a beam system with active piezoelectric fiber-reinforced composite layers. Then, more researches are reported on the MFC materials as sensors and actuators in different structures to adjust the deformation or vibration of the system, such as rotating composite thinwalled beams [2], thin beams [3], cylindrical shells [4], and smart composite plates [5].

Recently, the dynamic behaviors of the classical MFC structure are attracting more and more scholars from all over the world. Park and Kim [6] investigated the material properties of MFCs by using classical lamination theory and uniform field model. Bilgen et al. [7] built a linear distributed parameter electromechanical model for frequency-response analysis of MFC actuated clamped-free thin beams and compared their results with experimental results. Cook and Vel $[8,9]$ considered different stresses of a simply supported laminated plate consisting of an MFC shear actuator 
sandwiched between graphite/polymer layers, which were subjected to an electric field perpendicular to the poling direction.

The nonlinear dynamical simulations considering large displacements are taken into account for different MFC structures, such as circular plates [10], functionally graded plates [11], laminated composite plates [12], and thin-walled structures [13]. The effects of different parameters of the structures on the natural frequencies and vibration modes are discussed in these articles. Similarly, actuation properties of MFCs under strong voltages were investigated by Williams et al. [14] through using the theoretical piezoelectric constitutive model with higher-order electric field. Zhang and Shen [15] conducted the three-dimensional analysis for rectangular 1-3 piezoelectric fiber-reinforced composite laminates with the interdigitated electrodes under electromechanical loadings. Belouettar et al. [16] investigated active control of nonlinear vibrations of piezoelectric-elastic-piezoelectric sandwich beams using the method of harmonic balance.

Rafiee et al. [17] investigated the nonlinear vibration and dynamic behavior of simply supported piezoelectric functionally graded shells under electrical, thermal, mechanical, and aerodynamic loadings. Hosseini et al. [18] analyzed the nonlinear free and forced vibrations of cantilever structures resting on a nonlinear elastic foundation with a piecewise piezoelectric actuator layer bonded on the top surface. The effects of various parameters on the free and forced nonlinear responses of the system were discussed. Mareishi et al. [19] considered the geometric nonlinearity of the piezoelectric fiber-reinforced laminated composite beams and analyzed the nonlinear frequencies of the beams with simply supported and clamped boundary conditions. Rafiee et al. [20] provided numerical simulation about the nonlinear dynamics of piezoelectric nanotubes/fibers/polymer multiscale composite plates, including the effects of different parameters of single-walled carbon nanotubes (SWCNTs) and multiwalled carbon nanotubes (MWCNTs) on the linear and nonlinear natural frequencies. Ninh and Bich [21] studied the electrothermal mechanical vibration of functionally graded carbon nanotube-reinforced composite (FGCNTRC) cylindrical shells by the numerical analytical method. Lu et al. [22] investigated the nonlinear dynamic characteristics of the time-varying piezoelectric laminated composite plate.

In regard to the analysis methods for laminated composite plates with integrated piezoelectric actuators, several studies have been performed using the classical lamination theory [23], first-order shear deformation theory [24], higher-order theories [25], and the finite element method [26]. Moreover, Prasath and Arockiarajan [27, 28] studied the effect of bonding layer volume fraction on the effective thermo-electro-elastic constants of both $d 33$ - and d31-type MFCs by using the finite element method and experiments. Zhang et al. [29] investigated the structural deformation of composite laminated thin-walled structures bonded with orthotropic MFCs by establishing the finite element (FE) model based on linear piezoelectric constitutive equations.

There are many researches on the aerodynamic force of different structures. Kouchakzadeh et al. [30] analyzed the aerodynamic modeling of structures by applying the classical plate theory along with the von Karman nonlinear strains and linear piston theory. Li et al. [31] used the piezoelectric material to increase the flutter velocities of the supersonic beams and adopted the supersonic piston theory to evaluate the aerodynamic pressure. Kuo [32] investigated the influence of variable fiber spacing on the supersonic flutter of rectangular composite plates and later also [33] discussed the effects of hybrid fiber distribution on the critical buckling temperature, natural frequencies, and flutter boundary of composite laminates by using the finite element method. Zhang et al. [34] considered the aerodynamics of a deploying wing in subsonic air flow and investigated the nonlinear dynamic behaviors of deploying wings in numerical simulations.

Motivated by the above considerations, the nonlinear dynamic analysis of the MFC laminated shell subjected to aerodynamic force is presented here. The effects of piezoelectric properties and aerodynamic force on the dynamic stability of the structure are studied. Nonlinear dynamic equations of the cantilever MFC laminated shell are built based on UAV wings. The effect of different forces on the dynamic behaviors of MFC laminated shells is investigated in numerical simulation. Moderating effects of piezoelectric performance on the stability of the system are also presented here, which would provide guidance in controlling strategy of the nonlinear vibration for UAV wings.

\section{Derivation of the Aerodynamic Force on the Deploying Wing}

Considering the work situation of UAVs in subsonic air flow, the thin airfoil theory is applied here to calculate aerodynamic forces. Based on the thin airfoil theory, the potential function of the flow field can be divided into two parts: one is the potential function of the original uniform flow and the other is the disturbance potential function generated by the perturbation of the airfoil convection field, which also satisfies Laplace equations. Moreover, the perturbed potential function can be obtained according to the boundary condition of the typical airfoil and the infinite boundary condition of velocity approaching zero, as shown in Figure 1.

Therefore, the boundary condition can be given as follows:

$$
\alpha+\frac{V_{n}}{V_{\infty}}=\frac{d y}{d x},
$$

where $\alpha$ is the angle of attack, $V_{n}$ is the normal induced velocity, $V_{\infty}$ is the uniform flow velocity in direction $\alpha$, and $d y / d x$ means the slope at any point in the middle arc of the airfoil.

Furthermore, the disturbance potential function equations and boundary conditions can be expressed in terms of the airfoil thickness and velocity potential caused by the camber curvature and attacked angle. When the curvature of the camber line is very small, the vorticity gradient in the $y$ 


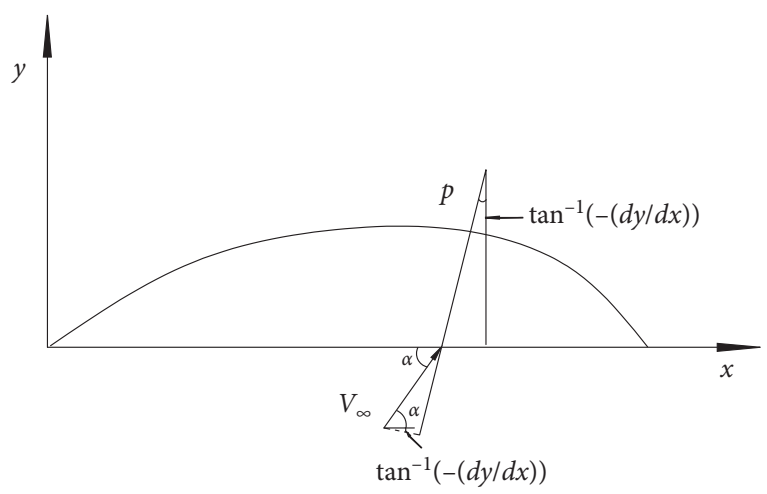

FIgURE 1: Normal velocity of the free stream in the middle curve.

direction is small with respect to a small camber or curvature, as shown in Figure 2.

Therefore, the total circulation of the entire airfoil is expressed as follows:

$$
\Gamma=\int_{0}^{c} \gamma d \xi
$$

and the boundary condition is transformed into the following form:

$$
\alpha+\frac{1}{V_{\infty}} \int_{0}^{c} \frac{\gamma(\xi) d \xi}{2 \pi(\xi-x)}=\frac{d y}{d x},
$$

where $\gamma(\xi)$ can be expanded to a Fourier series of $\gamma(\theta)$ :

$$
\gamma(\theta)=2 V_{\infty}\left(A_{0} \cot \left(\frac{\theta}{2}\right)+\sum_{1}^{\infty} A_{n} \sin (n \theta)\right) .
$$

Moreover, the boundary conditions are obtained as follows through the transformation $x=(b / 2)(1-\cos \Theta)$ :

$$
\begin{aligned}
\alpha-A_{0} & =\frac{1}{\pi} \int_{0}^{\pi} \frac{d y}{d x} d \Theta, \\
A_{n} & =\frac{2}{\pi} \int_{0}^{\pi}\left(\frac{d y}{d x}\right) \cos (n \Theta) d \Theta .
\end{aligned}
$$

Therefore, the total circulation can be rewritten as

$$
\begin{aligned}
\Gamma= & \int_{0}^{c} \gamma(x) d x=V_{\infty} b \int_{0}^{\pi}\left[A_{0}(1+\cos \Theta)\right. \\
& \left.+\sum_{1}^{\infty} A_{n} \sin (n \Theta) \sin \Theta\right]=\pi \alpha b V_{\infty},
\end{aligned}
$$

and the lift per unit wingspan is expressed as

$$
L=\pi \alpha \rho b V_{\infty}^{2} .
$$

Finally, the total lift on wingspan can be obtained according to the typical airfoil shape modeled in the following sections.

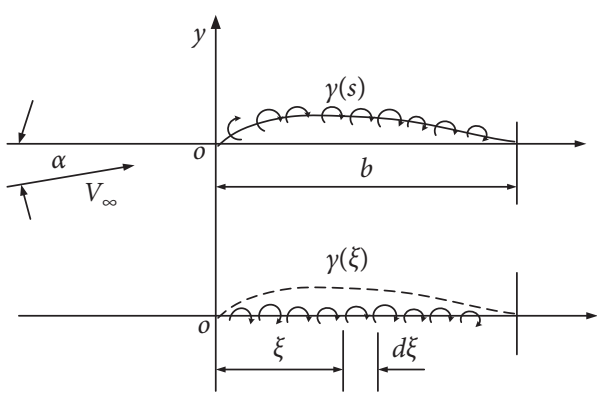

FIgURe 2: Circulation distribution along the airfoil.

\section{Mechanical Model}

Generally, the induced strain of the $d 33$ piezoelectric constant is larger than that of the $d 31$ piezoelectric constant for MFC materials. Therefore, a $d 33$ MFC laminated hyperbolic shell is considered here to establish the mechanical model of the high-aspect-ratio wings for UAVs. The cylindrical coordinate system is described here with curvatures $\alpha$ and $\beta$ on the middle surface and perpendicular to the middle surface of the shell, as shown in Figure 3. The Cartesian coordinate system Oxyz is located in the tangent plane of the thin shell. Geometric dimensions of the shell are the lengths $a$ and $b$ and the thickness $h$, and the principal radii of the curvatures are $R_{3}$ and $R_{4}$. The displacements of an arbitrary point within the shell are expressed as $u, v$, and $w$, respectively. $w$ is taken as a positive vector going outward from the center of the smallest radius of the curvature. The shell is subjected to the aerodynamic force as $q=f \cos \left(\Omega_{2} t\right)$. A dynamic electric field is expressed as $E=E \cos \left(\Omega_{1} t\right)$ and applied in the longitudinal direction of the piezoelectric fibers, as shown in Figure 4.

All piezoelectric fibers are considered to be poled in the $\alpha$ and $\beta$ directions, which can be assumed that out-of-plane electric fields vanish (that is, $e_{33}=0$ ). Therefore, three sets of material coefficients are used to address the constitutive characteristics of the mechanical and electrical fields as well as the coupling between these fields, as follows:

$$
\begin{aligned}
\sigma_{p} & =C_{p q} \varepsilon_{q}-e_{k p} E_{k}, \\
D_{i} & =e_{i q} \varepsilon_{q}+k_{i k} E_{k},
\end{aligned}
$$

where $E_{k}$ is the electric field intensity, $\sigma_{p}$ is the stress, $\varepsilon_{q}$ is the strain, $C_{p q}$ is the coefficient of elasticity, $D_{i}$ is the electric displacement, and $e_{k p}$ and $k_{i k}$ represent the piezoelectric constants.

Using the nonlinear von Karman's geometric relationship for the thin shell, the strain can be expressed as

$$
\begin{aligned}
& \varepsilon_{1}=\varepsilon_{1}^{0}+\eta \varepsilon_{1}^{1}+\eta^{3} \varepsilon_{1}^{2}, \\
& \varepsilon_{2}=\varepsilon_{2}^{0}+\eta \varepsilon_{2}^{1}+\eta^{3} \varepsilon_{2}^{2}, \\
& \varepsilon_{4}=\varepsilon_{4}^{0}+\eta^{2} \varepsilon_{4}^{1}, \\
& \varepsilon_{5}=\varepsilon_{5}^{0}+\eta^{2} \varepsilon_{5}^{1}, \\
& \varepsilon_{6}=\varepsilon_{6}^{0}+\eta \varepsilon_{6}^{1}+\eta^{3} \varepsilon_{6}^{2},
\end{aligned}
$$

where $\varepsilon_{1}^{0}, \varepsilon_{1}^{1}$, and $\varepsilon_{1}^{2}$ are described as 


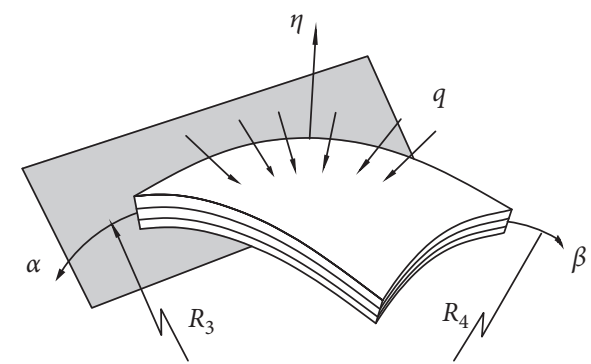

Figure 3: Model of the MFC thin shell.

$\varepsilon_{1}^{0}=\frac{\partial u_{0}}{\partial x}+\frac{w_{0}}{R_{3}}+\frac{1}{2}\left(\frac{\partial w_{0}}{\partial x}\right)^{2}$

$\varepsilon_{1}^{1}=\frac{\partial \phi_{1}}{\partial x}$

$\varepsilon_{1}^{2}=-c_{1}\left(\frac{\partial \phi_{1}}{\partial x}+\frac{\partial^{2} w_{0}}{\partial x^{2}}-\frac{1}{R_{3}} \frac{\partial u_{0}}{\partial x}\right)$

$\varepsilon_{2}^{0}=\frac{\partial v_{0}}{\partial y}+\frac{w_{0}}{R_{4}}+\frac{1}{2}\left(\frac{\partial w_{0}}{\partial y}\right)^{2}$

$\varepsilon_{2}^{1}=\frac{\partial \phi_{2}}{\partial y}$

$\varepsilon_{2}^{2}=-c_{1}\left(\frac{\partial \phi_{2}}{\partial y}+\frac{\partial^{2} w_{0}}{\partial y^{2}}-\frac{1}{R_{4}} \frac{\partial v_{0}}{\partial y}\right)$

$\varepsilon_{4}^{0}=\phi_{2}+\frac{\partial w_{0}}{\partial y}-\frac{v_{0}}{R_{4}}$

$\varepsilon_{4}^{1}=-c_{2}\left(\phi_{2}+\frac{\partial w_{0}}{\partial y}-\frac{v_{0}}{R_{4}}\right)$

$\varepsilon_{5}^{0}=\phi_{1}+\frac{\partial w_{0}}{\partial x}-\frac{u_{0}}{R_{4}}$

$\varepsilon_{5}^{1}=-c_{2}\left(\phi_{1}+\frac{\partial w_{0}}{\partial x}-\frac{u_{0}}{R_{3}}\right)$

$\varepsilon_{6}^{0}=\frac{\partial u_{0}}{\partial y}+\frac{\partial v_{0}}{\partial x}+\frac{\partial w_{0}}{\partial x} \frac{\partial w_{0}}{\partial y}$

$\varepsilon_{6}^{1}=\frac{\partial \phi_{1}}{\partial y}+\frac{\partial \phi_{2}}{\partial x}$

$\varepsilon_{6}^{2}=-c_{1}\left(\frac{\partial \phi_{1}}{\partial y}+\frac{\partial \phi_{2}}{\partial x}+2 \frac{\partial^{2} w_{0}}{\partial x \partial y}-\frac{1}{R_{3}} \frac{\partial u_{0}}{\partial y}-\frac{1}{R_{4}} \frac{\partial v_{0}}{\partial x}\right)$.
The Lame coefficients of the shells $A_{1}$ and $A_{2}$ are expressed as

$$
\begin{aligned}
& A_{1}=a_{1}\left(1+\frac{\eta}{R_{3}}\right)=\sqrt{\Lambda_{11}}, \\
& A_{2}=a_{2}\left(1+\frac{\eta}{R_{4}}\right)=\sqrt{\Lambda_{22}},
\end{aligned}
$$

where $a_{i}(1,2)$ is the surface tensor of the shell.

The displacement of an arbitrary point in the composite shell can be expressed as $R$ and be calculated as follows:

$$
d R=\sqrt{\Lambda_{11}} d \alpha+\sqrt{\Lambda_{22}} d \beta+\widehat{n} d \eta,
$$

where $\widehat{n}$ is the unit vector perpendicular to the middle plane of the shell, which is expressed as follows:

$$
\widehat{n}=\frac{g_{1} \times g_{2}}{a_{1} a_{2}} \text {. }
$$

Here, $g_{i}(1,2)$ is the vector tangent to the cylindrical coordinate axis.

Since the following analysis is carried out in the Cartesian coordinate system, it needs the relations between the cylindrical coordinate system and the Cartesian coordinate system:

$$
\left\{\begin{array}{l}
d x \\
d y \\
d z
\end{array}\right\}=\left[\begin{array}{ccc}
a_{1} & 0 & 0 \\
0 & a_{2} & 0 \\
0 & 0 & 1
\end{array}\right]\left\{\begin{array}{l}
d \alpha \\
d \beta \\
d \eta
\end{array}\right\} .
$$

The displacement field at an arbitrary point in the composite shell is given as follows based on Reddy's thirdorder theory:

$$
\begin{aligned}
& u=u_{0}(x, y, t)+z \phi_{1}(x, y, t)-\frac{4}{3 h^{2}} z^{3}\left(\phi_{1}+\frac{\partial w_{0}}{\partial \alpha}\right) \\
& v=v_{0}(x, y, t)+z \phi_{2}(x, y, t)-\frac{4}{3 h^{2}} z^{3}\left(\phi_{2}+\frac{\partial w_{0}}{\partial \beta}\right) \\
& w=w_{0}(x, y, t)
\end{aligned}
$$




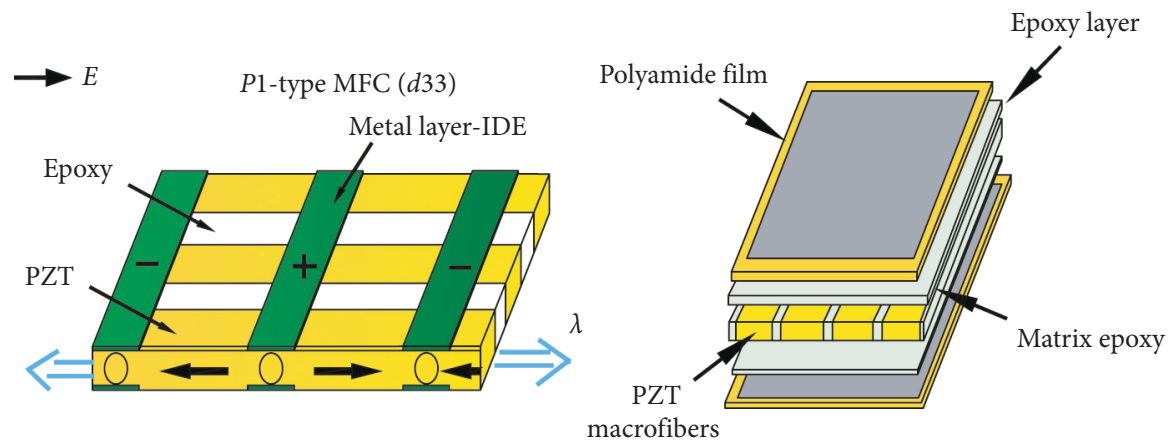

FIgURE 4: MFC-d33 material.

where $u_{0}, v_{0}$, and $w_{0}$ are the original displacements at the midplane of the MFC shell in the Cartesian coordinate directions and $\phi_{1}$ and $\phi_{2}$ represent the rotations of transverse normal at the midplane about the $y$ and $x$ axes.

The aerodynamic force in the shell structure can be calculated as follows:

$$
q=\int_{l} L d s=\pi \alpha \rho b V_{\infty}^{2} a .
$$

Substituting these transformations into equations (15a)-(15c) and applying Hamilton's principle, the nonlinear governing equations of motion in terms of generalized displacements for the MFC thin shell can be obtained as follows:

$$
\begin{aligned}
& -a_{11} \frac{\partial^{3} w_{0}}{\partial x^{3}}+a_{12} \frac{\partial w_{0}}{\partial x} \frac{\partial^{2} w_{0}}{\partial x^{2}}+a_{13} \frac{\partial w_{0}}{\partial y} \frac{\partial^{2} w_{0}}{\partial x \partial y}+a_{14} \frac{\partial w_{0}}{\partial x} \frac{\partial^{2} w_{0}}{\partial y^{2}} \\
& -a_{15} \frac{\partial^{3} w_{0}}{\partial x \partial y^{2}}+a_{16} \frac{\partial w_{0}}{\partial x}+a_{17} \frac{\partial^{2} u_{0}}{\partial x^{2}}+a_{18} \frac{\partial^{2} u_{0}}{\partial y^{2}}+a_{19} \frac{\partial^{2} v_{0}}{\partial x \partial y} \\
& +a_{20} \frac{\partial^{2} \phi_{1}}{\partial x^{2}}+a_{21} \frac{\partial^{2} \phi_{1}}{\partial y^{2}}+a_{22} \frac{\partial^{2} \phi_{2}}{\partial x \partial y}+a_{23} u_{0}+a_{24} \phi_{1} \\
& -a_{25} E_{1} \cos \left(\Omega_{1} t\right)=I_{0} \ddot{u}_{0}, \\
& -b_{11} \frac{\partial^{3} w_{0}}{\partial y^{3}}+b_{12} \frac{\partial w_{0}}{\partial y} \frac{\partial^{2} w_{0}}{\partial y^{2}}+b_{13} \frac{\partial w_{0}}{\partial x} \frac{\partial^{2} w_{0}}{\partial x \partial y}+b_{14} \frac{\partial w_{0}}{\partial y} \frac{\partial^{2} w_{0}}{\partial x^{2}} \\
& -b_{15} \frac{\partial^{3} w_{0}}{\partial y \partial x^{2}}+b_{16} \frac{\partial w_{0}}{\partial y}+b_{17} \frac{\partial^{2} v_{0}}{\partial x^{2}}+b_{18} \frac{\partial^{2} v_{0}}{\partial y^{2}}+b_{19} \frac{\partial^{2} u_{0}}{\partial x \partial y} \\
& +b_{20} \frac{\partial^{2} \phi_{2}}{\partial x^{2}}+b_{21} \frac{\partial^{2} \phi_{2}}{\partial y^{2}}+b_{22} \frac{\partial^{2} \phi_{1}}{\partial x \partial y}+b_{23} v_{0}+b_{24} \phi_{2} \\
& -b_{25} E_{2} \cos \left(\Omega_{1} t\right)=I_{0} \ddot{v}_{0},
\end{aligned}
$$

$$
\begin{aligned}
& -c_{11} \frac{\partial^{4} w_{0}}{\partial x^{4}}-c_{12} \frac{\partial^{4} w_{0}}{\partial y^{4}}-c_{13} \frac{\partial^{4} w_{0}}{\partial x^{2} \partial y^{2}}+c_{14} \frac{\partial^{2} w_{0}}{\partial x^{2}} \\
& +c_{15} \frac{\partial^{2} w_{0}}{\partial y^{2}}+c_{16}\left(\frac{\partial w_{0}}{\partial x}\right)^{2}+c_{17}\left(\frac{\partial w_{0}}{\partial y}\right)^{2}+c_{18} \frac{\partial^{2} w_{0}}{\partial x^{2}} \frac{\partial v_{0}}{\partial x} \\
& +c_{19} \frac{\partial^{2} w_{0}}{\partial y^{2}} \frac{\partial v_{0}}{\partial y}+c_{20} \frac{\partial w_{0}}{\partial x} \frac{\partial^{2} u_{0}}{\partial x^{2}}+c_{21} \frac{\partial w_{0}}{\partial y} \frac{\partial^{2} v_{0}}{\partial y^{2}} \\
& +c_{22} w_{0} \frac{\partial^{2} w_{0}}{\partial x^{2}}+c_{23} w_{0} \frac{\partial^{2} w_{0}}{\partial y^{2}}+c_{24}\left(\frac{\partial w_{0}}{\partial x}\right)^{2} \frac{\partial^{2} w_{0}}{\partial x^{2}} \\
& +c_{25}\left(\frac{\partial w_{0}}{\partial y}\right)^{2} \frac{\partial^{2} w_{0}}{\partial y^{2}}+c_{26}\left(\frac{\partial w_{0}}{\partial y}\right)^{2} \frac{\partial^{2} w_{0}}{\partial x^{2}}+c_{27}\left(\frac{\partial w_{0}}{\partial x}\right)^{2} \frac{\partial^{2} w_{0}}{\partial y^{2}} \\
& +c_{28} \frac{\partial^{2} w_{0}}{\partial x^{2}} \frac{\partial v_{0}}{\partial y}+c_{29} \frac{\partial^{2} w_{0}}{\partial y^{2}} \frac{\partial u_{0}}{\partial x}+c_{30} \frac{\partial w_{0}}{\partial x} \frac{\partial^{2} v_{0}}{\partial x \partial y} \\
& +c_{31} \frac{\partial w_{0}}{\partial y} \frac{\partial^{2} u_{0}}{\partial x \partial y}+c_{32} \frac{\partial w_{0}}{\partial x} \frac{\partial w_{0}}{\partial y} \frac{\partial^{2} w_{0}}{\partial x \partial y}+c_{33} \frac{\partial^{2} w_{0}}{\partial x \partial y} \frac{\partial v_{0}}{\partial x} \\
& +c_{34} \frac{\partial^{2} w_{0}}{\partial x \partial y} \frac{\partial u_{0}}{\partial y}+c_{35} \frac{\partial w_{0}}{\partial y} \frac{\partial^{2} v_{0}}{\partial x^{2}}+c_{36} \frac{\partial w_{0}}{\partial x} \frac{\partial^{2} u_{0}}{\partial y^{2}} \\
& -c_{37} \frac{\partial w_{0}}{\partial y} \frac{\partial^{3} w_{0}}{\partial x^{2} \partial y}-c_{38} \frac{\partial^{3} w_{0}}{\partial x \partial y^{2}} \frac{\partial w_{0}}{\partial x}+c_{39} \frac{\partial^{3} u_{0}}{\partial x^{3}} \\
& +c_{40} \frac{\partial^{3} v_{0}}{\partial y^{3}}-c_{41} \frac{\partial u_{0}}{\partial x}-c_{42} \frac{\partial v_{0}}{\partial y}+c_{43} \frac{\partial^{3} u_{0}}{\partial x \partial y^{2}}+c_{44} \frac{\partial^{3} v_{0}}{\partial x^{2} \partial y} \\
& +c_{45} \frac{\partial^{3} \phi_{1}}{\partial x^{3}}+c_{46} \frac{\partial^{3} \phi_{2}}{\partial y^{3}}+c_{47} \frac{\partial^{3} \phi_{1}}{\partial x \partial y^{2}}+c_{48} \frac{\partial^{3} \phi_{2}}{\partial x^{2} \partial y} \\
& +c_{49} \frac{\partial \phi_{1}}{\partial x}+c_{50} \frac{\partial \phi_{2}}{\partial y}-c_{51} w_{0}+f \cos \left(\Omega_{2} t\right)-\mu \dot{w}_{0}=I_{0} \ddot{w}_{0} \\
& +\left(c_{1} I_{4}-c_{1}^{3} I_{6}\right)\left(\frac{\partial \ddot{\phi}_{1}}{\partial x}+\frac{\partial \ddot{\phi}_{2}}{\partial y}\right)+c_{1}^{3} I_{6}\left(\frac{\partial^{2} \ddot{w}_{0}}{\partial x^{2}}+\frac{\partial \ddot{w}_{0}}{\partial y^{2}}\right),
\end{aligned}
$$




$$
\begin{aligned}
& d_{11} \frac{\partial^{3} w_{0}}{\partial x^{3}}+d_{12} \frac{\partial^{3} w_{0}}{\partial x \partial y^{2}}+d_{13} \frac{\partial w_{0}}{\partial x} \frac{\partial^{2} w_{0}}{\partial y^{2}} \\
& \quad+d_{14} \frac{\partial w_{0}}{\partial y} \frac{\partial^{2} w_{0}}{\partial x \partial y}+d_{15} \frac{\partial w_{0}}{\partial x}+d_{16} \frac{\partial^{2} u_{0}}{\partial x^{2}}+d_{17} \frac{\partial^{2} u_{0}}{\partial y^{2}} \\
& \quad+d_{18} \frac{\partial^{2} v_{0}}{\partial x \partial y}+d_{19} \frac{\partial^{2} \phi_{1}}{\partial x^{2}}+d_{20} \frac{\partial^{2} \phi_{1}}{\partial y^{2}}+d_{21} \frac{\partial^{2} \phi_{2}}{\partial x \partial y}+d_{22} u_{0} \\
& \quad+d_{23} \phi_{1}+d_{24} E_{1} \cos \left(\Omega_{1} t\right) \\
& =I_{2} \ddot{\phi}_{1}-c_{1} I_{4} \ddot{\phi}_{1}-c_{1} I_{4} \frac{\partial \ddot{w}_{0}}{\partial x}+c_{1}\left(-I_{4} \ddot{\phi}_{1}+c_{1} I_{6} \ddot{\phi}_{1}+c_{1} I_{6} \frac{\partial \ddot{w}_{0}}{\partial x}\right),
\end{aligned}
$$

$$
\begin{aligned}
& e_{11} \frac{\partial^{3} w_{0}}{\partial y^{3}}+e_{12} \frac{\partial^{3} w_{0}}{\partial x^{2} \partial y}+e_{13} \frac{\partial w_{0}}{\partial y} \frac{\partial^{2} w_{0}}{\partial x^{2}}+e_{14} \frac{\partial w_{0}}{\partial x} \frac{\partial^{2} w_{0}}{\partial x \partial y} \\
& \quad+e_{15} \frac{\partial w_{0}}{\partial y}+e_{16} \frac{\partial^{2} v_{0}}{\partial x^{2}}+e_{17} \frac{\partial^{2} v_{0}}{\partial y^{2}}+e_{18} \frac{\partial^{2} u_{0}}{\partial x \partial y}+e_{19} \frac{\partial^{2} \phi_{2}}{\partial x^{2}} \\
& \quad+e_{20} \frac{\partial^{2} \phi_{2}}{\partial y^{2}}+e_{21} \frac{\partial^{2} \phi_{1}}{\partial x \partial y}+e_{22} v_{0}+e_{23} \phi_{2}+e_{24} E_{2} \cos \left(\Omega_{1} t\right) \\
& =I_{2} \ddot{\phi}_{2}-c_{1} I_{4} \ddot{\phi}_{2}-c_{1} I_{4} \frac{\partial \ddot{w}_{0}}{\partial y}+c_{1}\left(-I_{4} \ddot{\phi}_{2}+c_{1} I_{6} \ddot{\phi}_{2}+c_{1} I_{6} \frac{\partial \ddot{w}_{0}}{\partial y}\right),
\end{aligned}
$$

where $\mu$ in equation (17c) is the damping coefficient.

The boundary conditions of the cantilever thin shell are expressed as

$$
\begin{gathered}
x=0: N_{x y}=M_{x x}=M_{x y}-c_{1} P_{x y}=\bar{Q}_{x}=0, \\
x=a: N_{x y}=M_{x x}=M_{x y}-c_{1} P_{x y}=\bar{Q}_{x}=0, \\
y=0: u_{0}=v_{0}=w_{0}=\phi_{1}=\phi_{2}=0, \\
y=b: N_{y y}=N_{x y}=M_{y y}=M_{x y} \\
\quad-c_{1} P_{x y}=\bar{Q}_{y}=0, \\
x=0, \\
a: \int_{-(h / 2)}^{(h / 2)} N_{x x} d z= \pm \int_{-(h / 2)}^{(h / 2)} f d z .
\end{gathered}
$$

\section{Effects of the Piezoelectric Parameters}

Since the polarization of MFC-d33 is located in the plane, the vibration amplitudes of the shell in the $x$ direction also need to be analyzed as those in the $z$ direction. Here, the nonlinear coupled vibrations are considered between the in-plane and out-of-plane of the cantilever shell in the following studies. The displacements $u_{0}, v_{0}, w_{0}, \phi_{1}$, and $\phi_{2}$, which satisfy the boundary conditions for the shell, are expressed as

$$
\begin{aligned}
u_{0}= & u_{1} \sin \frac{\pi x}{2} \cos \pi y, \\
v_{0}= & v_{1} \sin \frac{\pi x}{2} \sin \pi y, \\
\phi_{1}= & \phi_{11} \sin \frac{\pi x}{2} \cos \pi y, \\
\phi_{2}= & \phi_{21}\left(1-\cos \frac{\pi x}{2}\right) \sin \pi y, \\
w_{0}= & w_{1}(t) X(x) Y(y), \\
X(x)= & \sin \lambda_{1} x-\sinh \lambda_{1} x \\
& +\alpha_{1}\left(\cosh \lambda_{1} x-\cos \lambda_{1} x\right), \\
Y(y)= & \sqrt{3}\left(1-\frac{2 y}{b}\right),
\end{aligned}
$$

Then, taking all these derived expressions in equations (18a)-(18e) and (19a)-(19c) into equations (17a)-(17e) and applying the Galerkin procedure, two-degree-of-freedom nonlinear ordinary differential equations of the MFC laminated shell with dimensionless variables are obtained as follows:

$$
\begin{aligned}
& \ddot{u}_{1}+\omega_{1}^{2} u_{1}+\alpha_{11} w_{1}^{2}+\alpha_{12} E_{1} \cos \left(\Omega_{1} t\right)=0 \\
& \ddot{w}_{1}+\mu_{1} \dot{w}_{1}+\omega_{2}^{2} w_{1}+\alpha_{21} u_{1}+\alpha_{22} u_{1} w_{1}+\alpha_{23} w_{1} E_{1} \cos \left(\Omega_{1} t\right) \\
& +\alpha_{24} w_{1}^{2}+\alpha_{25} w_{1}^{3}+\alpha_{26} E_{1} \cos \left(\Omega_{1} t\right)=\alpha_{27} f \cos \left(\Omega_{2} t\right)
\end{aligned}
$$

The structural properties are taken as follows: the shell has 7 laminae and the total thickness is $0.002 * 7 \mathrm{~m}$. The elastic constants of the fiber and matrix are $2.1 \times 10^{11} \mathrm{~Pa}$ and $3.5 \times 10^{9} \mathrm{~Pa}$, respectively. The destiny of the shell is $1.96 \mathrm{~kg} / \mathrm{m}^{3}$, and Poisson's ratio is 0.36 . The electric inductivity is 1296 , and piezoelectric coefficients are $d_{33}=509 \mathrm{pC} / \mathrm{N}$ and $d_{31}=-156 \mathrm{pC} / \mathrm{N}$.

Firstly, the effects of the piezoelectric parameters on the deflection $\left(K=x_{1} / b\right)$ of the shell are analyzed. Let voltage be $40 \mathrm{kV} / \mathrm{cm}$ along the $y$ direction, the volume of the fiber content be $18 \%$, and $K$ be $15^{\circ}$. The radii $R_{3}$ and $R_{4}$ are divided into two groups: (i) $R_{3}=1.5 \mathrm{~m}$ and $R_{4}=1.5 \sim 2.5 \mathrm{~m}$ and (ii) $R_{3}=3 \mathrm{~m}$ and $R_{4}=3 \sim 5 \mathrm{~m}$. The relations between the radii of curvature $R_{3}$ and $R_{4}$ and $K$ are described in Figure 5, which shows that the curves are nearly straight when $R_{3}$ and $R_{4}$ increase. Therefore, the piezoelectric parameters would not affect the deflection of the thin shell directly.

Then, the voltage is increased from $20 \mathrm{kV} / \mathrm{cm}$ to $60 \mathrm{kV} /$ $\mathrm{cm}$ and the radii are set as $R_{3}=1.5 \mathrm{~m}$ and $R_{4}=2 \mathrm{~m}$, as shown in Figure 6. It indicates that the deflection of the thin shell will be amplified with the increasing voltages. The 
0.1040 .1050 .1060 .1060 .1070 .1050 .1050 .1060 .1060 .1050 .106

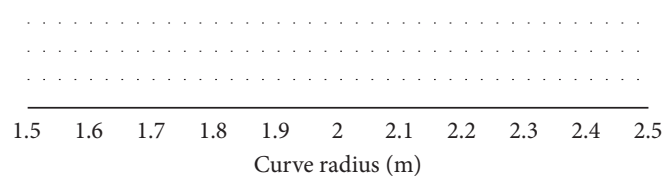

(a)
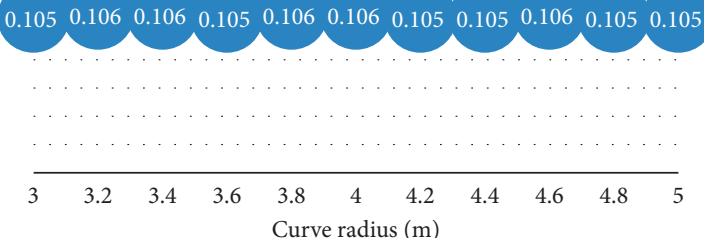

(b)

Figure 5: K-curve radius map.

deflection of the thin shell is also affected by the volume of macrofibers, as shown in Figure 7. The deflection $K$ increases from 1.2 to 11.7 when the volume of macrofibers varies from 0 to $20 \%$.

It is summarized from the above results that the voltage and volume of macrofibers play an important role in the deflection of the MFC shell, which could adjust the natural frequency of the shell. It also indicts that voltage and volume of macrofibers are useful controlling parameters for the dynamic responses of the shell.

5. Nonlinear Characteristic Analysis under 1:1 Internal Resonance. Since the resonance of the system has great influence on the structural stability, the primary parameter resonance and 1:1 internal resonance are considered here, and the resonance relationships are expressed as follows:

$$
\begin{aligned}
& \omega_{1}=\Omega_{1}-\varepsilon \sigma_{1}, \\
& \omega_{2}=\Omega_{2}-\varepsilon \sigma_{2}, \\
& \Omega_{1}=\Omega_{2}=1,
\end{aligned}
$$

where $\sigma_{1}$ and $\sigma_{2}$ are two detuning parameters, respectively.

The solution of equations (20a) and (20b) can be written as follows according to the method of multiscale:

$$
\begin{gathered}
u_{1}=u_{10}\left(T_{0}, T_{1}\right)+\varepsilon u_{11}\left(T_{0}, T_{1}\right)+\cdots, \\
w_{1}=w_{10}\left(T_{0}, T_{1}\right)+\varepsilon w_{11}\left(T_{0}, T_{1}\right)+\cdots .
\end{gathered}
$$

Equations (21), (22a), and (22b) are introduced into equations (20a) and (20b) to obtain the following conditions.

$\varepsilon^{0}$ order:

$$
\begin{aligned}
& D_{0}^{2} u_{10}+u_{10}=0, \\
& D_{0}^{2} w_{10}+w_{10}=0 .
\end{aligned}
$$

$\varepsilon^{1}$ order:

$$
\begin{gathered}
D_{0}^{2} u_{11}+u_{11}=-2 D_{0} D_{1} u_{10}-\alpha_{11} w_{10}^{2} \\
-\alpha_{12} E_{1} \cos \left(\Omega_{1} t\right)+2 \sigma_{1} u_{10}, \\
D_{0}^{2} w_{11}+w_{11}=-2 D_{0} D_{1} w_{10}-\mu_{1} D_{0} w_{10}-\alpha_{21} u_{10} \\
-\alpha_{22} u_{10} w_{10}-\alpha_{23} w_{10} E_{1} \cos \left(\Omega_{1} t\right) \\
+2 \sigma_{2} w_{10}-\alpha_{24} w_{10}^{2}-\alpha_{25} w_{10}^{3} \\
-\alpha_{26} E_{1} \cos \left(\Omega_{1} t\right)+\alpha_{27} F \cos \left(\Omega_{2} t\right) .
\end{gathered}
$$

Assume that the solutions of equations (24a) and (24b) are as follows:

$$
\begin{aligned}
& u_{10}=\prod_{1}\left(T_{1}\right) e^{i T_{0}}+c c, \\
& w_{10}=\prod_{2}\left(T_{1}\right) e^{i T_{0}}+c c,
\end{aligned}
$$

where $\Pi_{1}=(1 / 2) \varsigma_{1} e^{i \beta_{1}}$ and $\Pi_{2}=(1 / 2) \varsigma_{2} e^{i \beta_{2}}$, in which $\varsigma_{i}(i=$ $1,2)$ is the amplitude of vibration and $\beta_{i}(i=1,2)$ is the initial phase.

Substituting equations (25a) and (25b) into equations (24a) and (24b) and eliminating the long term, the average equations of the polar form are obtained as follows:

$$
\begin{aligned}
\dot{\zeta}_{1}= & -\frac{\alpha_{12}}{2} E_{1} \sin \left(\beta_{1}\right), \\
\varsigma_{1} \dot{\beta}_{1}= & -\frac{\alpha_{12}}{2} E_{1} \cos \left(\beta_{1}\right)-\varsigma_{1} \sigma_{1}, \\
\dot{\zeta}_{2}= & -\frac{1}{2} \mu \varsigma_{2}-\frac{1}{2} \alpha_{21} \varsigma_{1} \sin \left(\beta_{1}-\beta_{2}\right) \\
& -\frac{1}{2}\left(\alpha_{27} f-\alpha_{26} E_{1}\right) \sin \left(\beta_{2}\right), \\
\varsigma_{2} \dot{\beta}_{2}= & \frac{1}{2} \alpha_{21} \varsigma_{1} \cos \left(\beta_{1}-\beta_{2}\right)-\varsigma_{2} \sigma_{2} \\
& +\frac{3}{8} \alpha_{25} \varsigma_{2}^{3}+\frac{1}{2}\left(\alpha_{27} f-\alpha_{26} E_{1}\right) \cos \left(\beta_{2}\right) .
\end{aligned}
$$




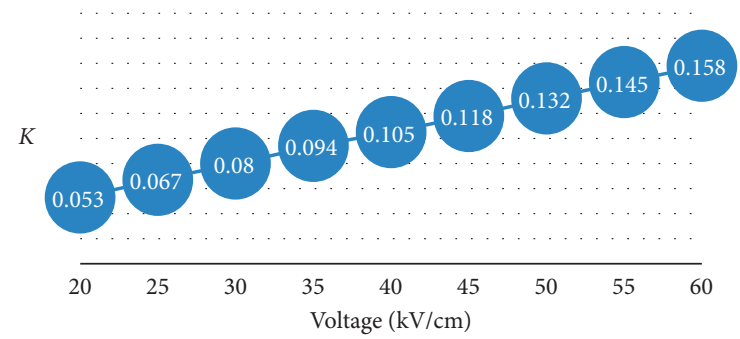

FIgURE 6: $K$-voltage map.

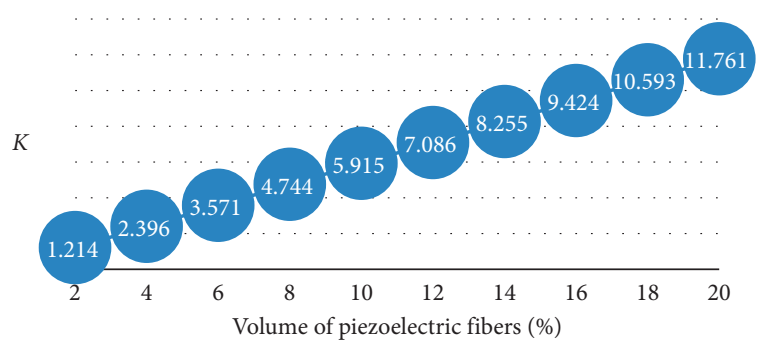

Figure 7: K-volume of macrofibers.

When the amplitude achieves a constant nontrivial value, a steady-state vibration exists. Therefore, let the lefthand side of equations (26a)-(26d) equals to zero and eliminate $\beta_{1}-\beta_{2}$ by using the relations between trigonometric functions, and then the frequency-response functions can be obtained:

$$
\begin{gathered}
\frac{\alpha_{12}^{2}}{4} E_{1}^{2}=\varsigma_{1}^{2} \sigma_{1}^{2} \\
\left(-\frac{1}{2} \mu \varsigma_{2}-\frac{1}{2}\left(\alpha_{27} f-\alpha_{26} E_{1}\right) \sin \left(\beta_{2}\right)\right)^{2} \\
+\left(-\varsigma_{2} \sigma_{2}+\frac{3}{8} \alpha_{25} \varsigma_{2}^{3}+\frac{1}{2}\left(\alpha_{27} f-\alpha_{26} E_{1}\right) \cos \left(\beta_{2}\right)\right)^{2}=\frac{1}{4} \alpha_{21}^{2} \varsigma_{1}^{2}
\end{gathered}
$$

Based on equations (27a) and (27b), the effects of electric field, transversal excitation, and nonlinear parameters $\left(\alpha_{25}\right)$ on the nonlinear amplitudes are investigated by numerical simulation. Fixing the parameters of the shell as mentioned above, and after the dimensionless calculation, the following parameters are obtained: $\alpha_{12}=6.7, \alpha_{25}=14.2$, $\alpha_{26}=9.9, \alpha_{27}=6.9, \alpha_{28}=12.5$, and $E_{1}=20$. Figure 8 illustrates that the resonance regions in the $x$ direction increase with the increasing electric field. The resonance region moves to the left in the $z$ direction and the resonance frequency decreases, as shown in Figure 9. Meanwhile, the system shows the hardening spring characteristic, as shown in Figure 9. Figure 10 expresses the relationship between the resonance region and the transversal excitation, which is similar to that shown in Figure 9. The nonlinear parameters can change the soft and hard spring properties of the system, as shown in Figure 11, and the hard spring characteristic is prominent with the nonlinear parameter increase.

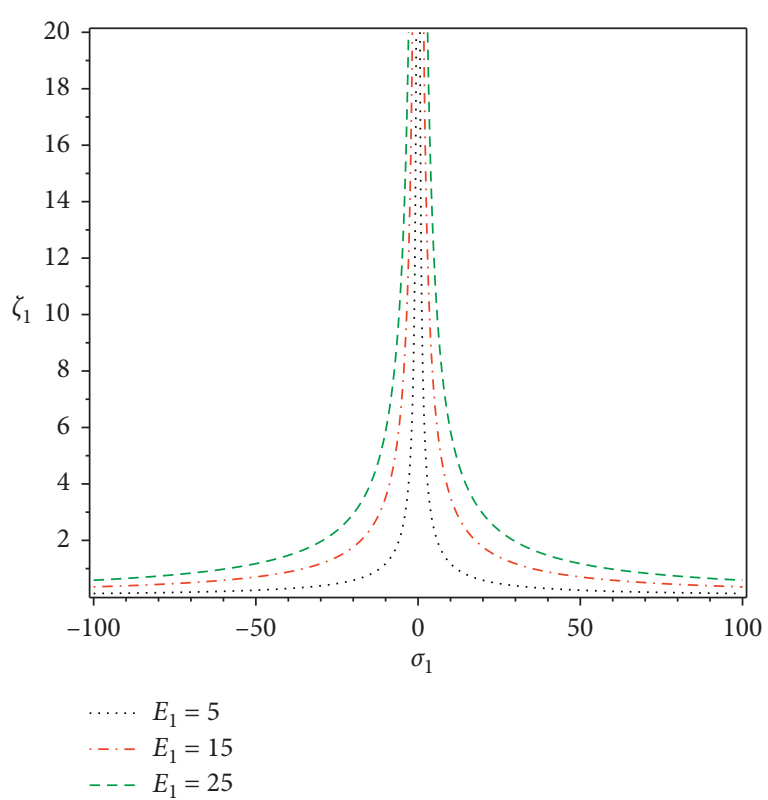

FIGURE 8: Frequency-response curves in the $x$ direction with the electric field.

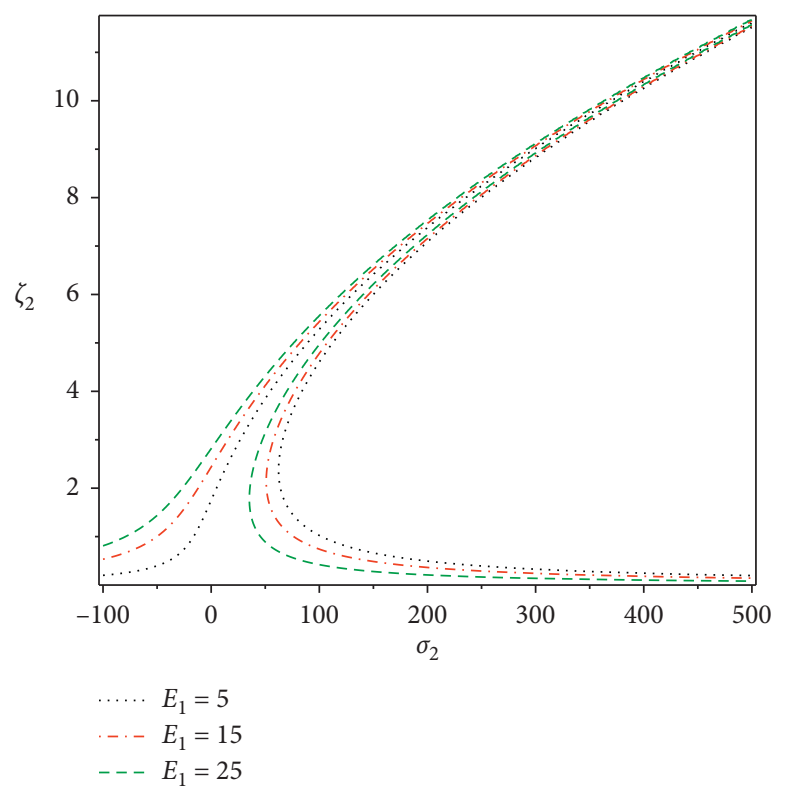

FIGURE 9: Frequency-response curves in the $z$ direction with the electric field.

\section{Nonlinear Dynamic Analysis}

In this section, the nonlinear dynamic behavior of the MFC laminated thin shell subjected to the aerodynamic force is conducted. A series of numerical experiments are performed through the Runge-Kutta algorithm according to the nonlinear governing equations (20a) and (20b). After the dimensionless calculation of the structural parameters, the following parameters are obtained: $\alpha_{11}=8.2, \alpha_{12}=6.7$, $\alpha_{13}=4.7, \mu=0.5, \alpha_{21}=12.7, \alpha_{22}=5.2, \alpha_{23}=8.0, \alpha_{24}=12.0$, $\alpha_{25}=14.2, \alpha_{26}=9.9, \alpha_{27}=6.9, \alpha_{28}=12.5, E_{1}=20, x_{1}=0.8$, 


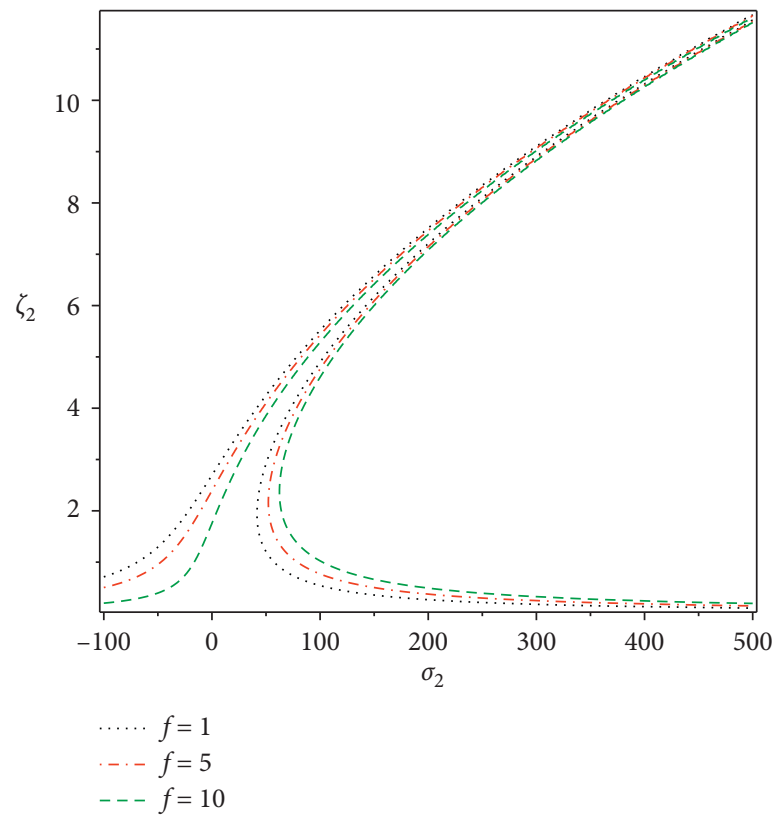

FIGURE 10: Frequency-response curves in the $z$ direction with transversal excitation.

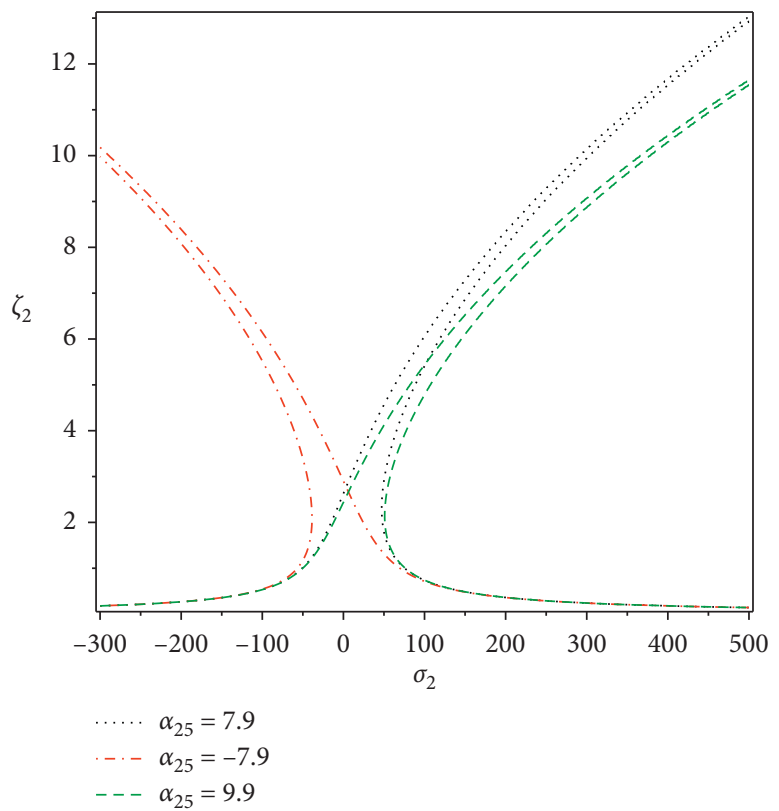

FIGURE 11: Frequency-response curves in the $z$ direction with the nonlinear parameter.

$x_{2}=1.0, x_{3}=0.2$, and $x_{4}=0.9$. With the disturbance force $f$ increased from 0 to 300 , the bifurcation diagrams of Poincare sections in the $z$ direction for the displacements of the middle surface of the shell are shown in Figure 12. It is found that the nonlinear responses of the shell are very complex with the increasing disturbance force $f$. The instability of the structure would last a long time during the process as $f$ increases from 0 to 180 , and then after short windows of periodic $n$ motions occurring in 180-230, the motions of the system become chaotic again through the path of periodic doubling bifurcation. Therefore, the motion form of the structure can be changed by controlling the amplitude of the external excitation in the resonance case.

To reveal the specific forms of different sections in the bifurcation diagram, phase portraits, power spectra, and waveforms of the shell are depicted as shown in the following figures. In Figures 13-15, $x_{1}$ and $x_{2}$ represent the displacement and velocity in the $x$ direction and $x_{3}$ and $x_{4}$ represent the displacement and velocity in the $z$ direction. Furthermore, Figures 13(a), 14(a), and 15(a) and Figures 13(b), 14(b), and 15(b) show, respectively, the waveforms in the planes $\left(t, x_{1}\right)$ and $\left(t, x_{3}\right)$, and Figures 13(c), 14(c), and 15(c) and Figures 13(d), 14(d), and 15(d) show, respectively, the 


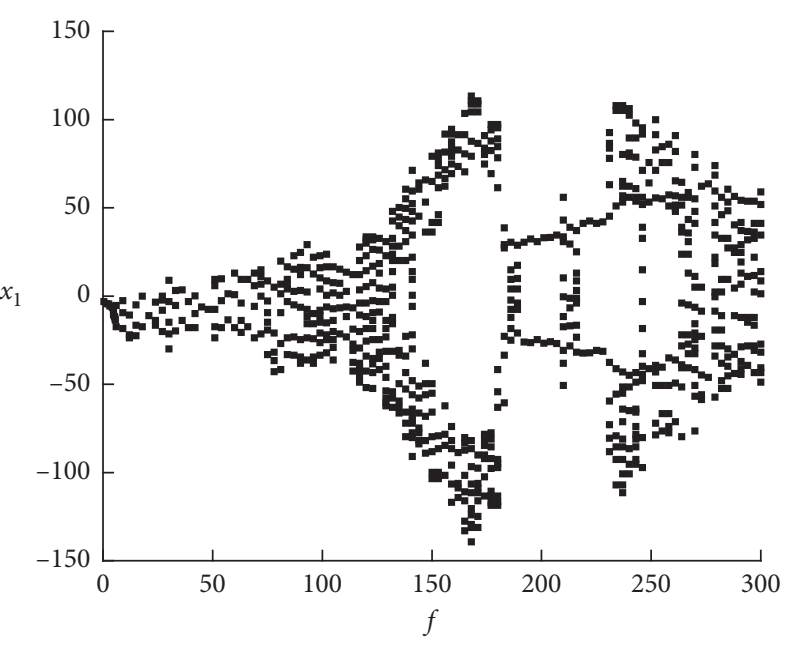

(a)

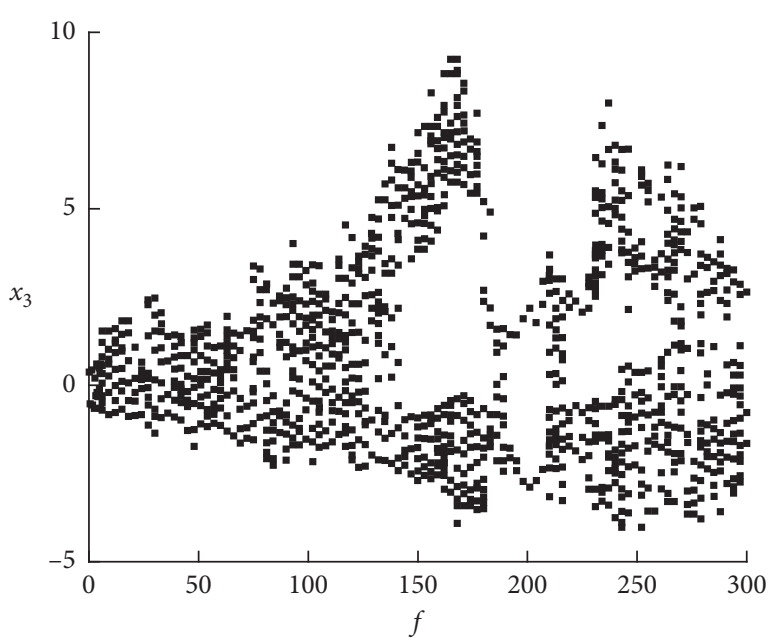

(b)

Figure 12: Bifurcation diagrams of Poincare sections. (a) $x_{1}-f$. (b) $x_{3}-f$.

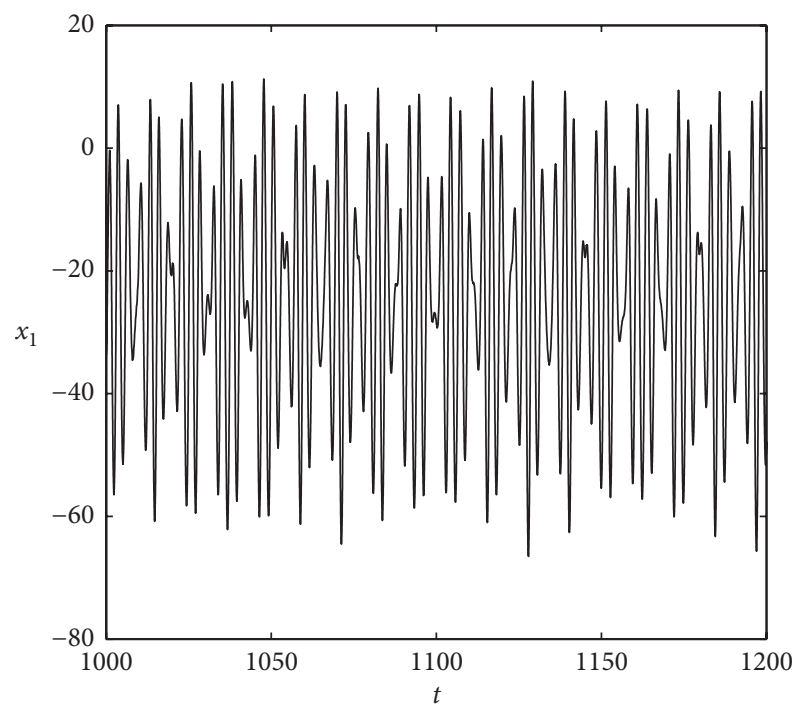

(a)

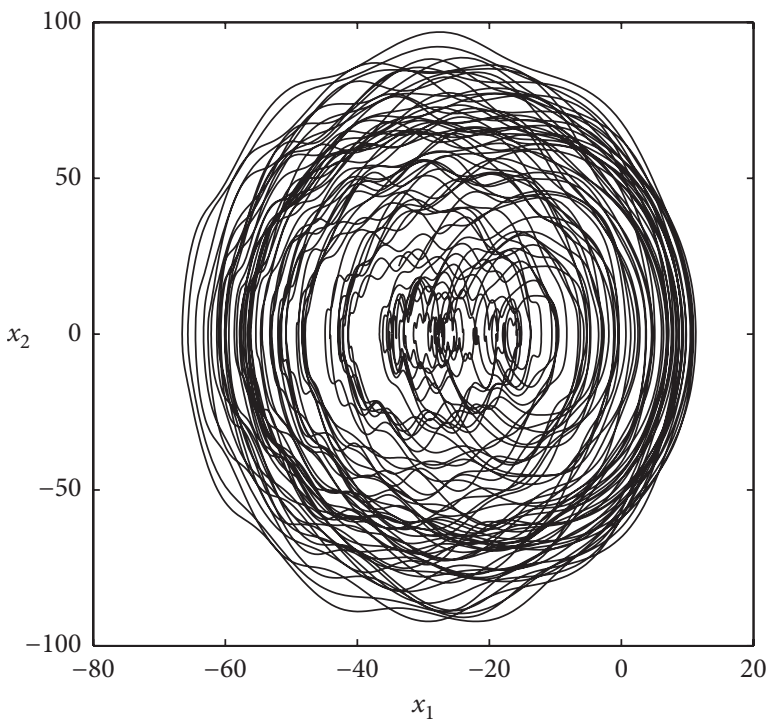

(c)

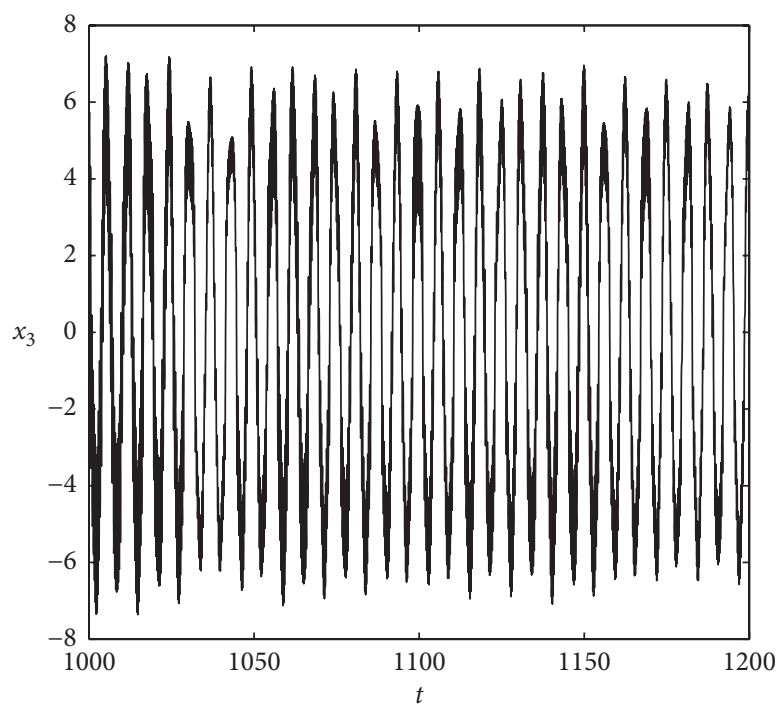

(b)

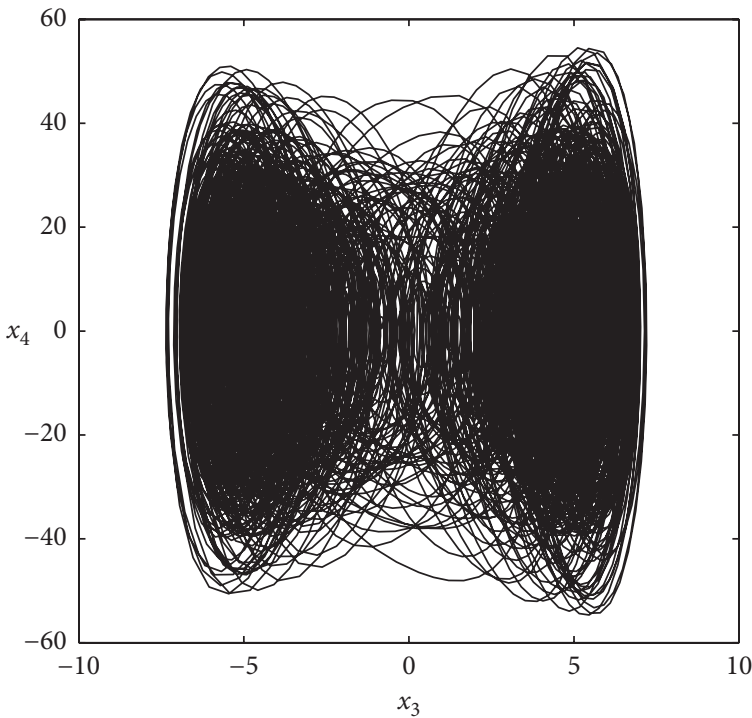

(d)

Figure 13: Continued. 


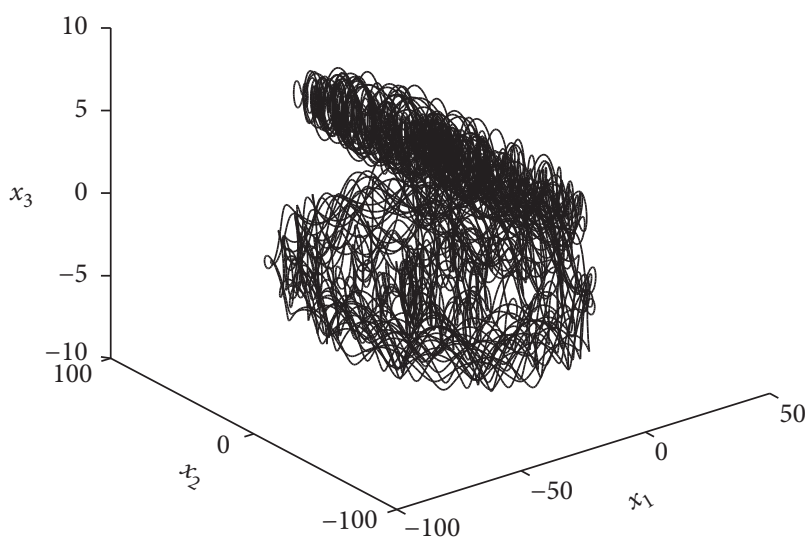

(e)

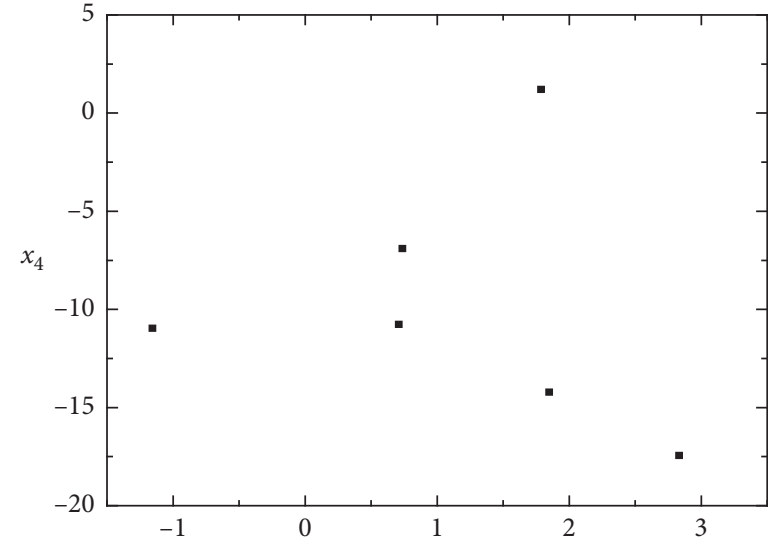

(f) $x_{3}$

FIgURE 13: Chaotic motion of the composite shell when $f$ equals 100. (a) Waveform in the plane $\left(t, x_{1}\right)$. (b) Waveform in the plane $\left(t, x_{3}\right)$. (c) Two-dimensional phase portrait in the plane $\left(x_{1}, x_{2}\right)$. (d) Two-dimensional phase portrait in the plane $\left(x_{3}, x_{4}\right)$. (e) Three-dimensional phase portrait in the plane $\left(x_{1}, x_{2}, x_{3}\right)$. (f) Poincare diagram.

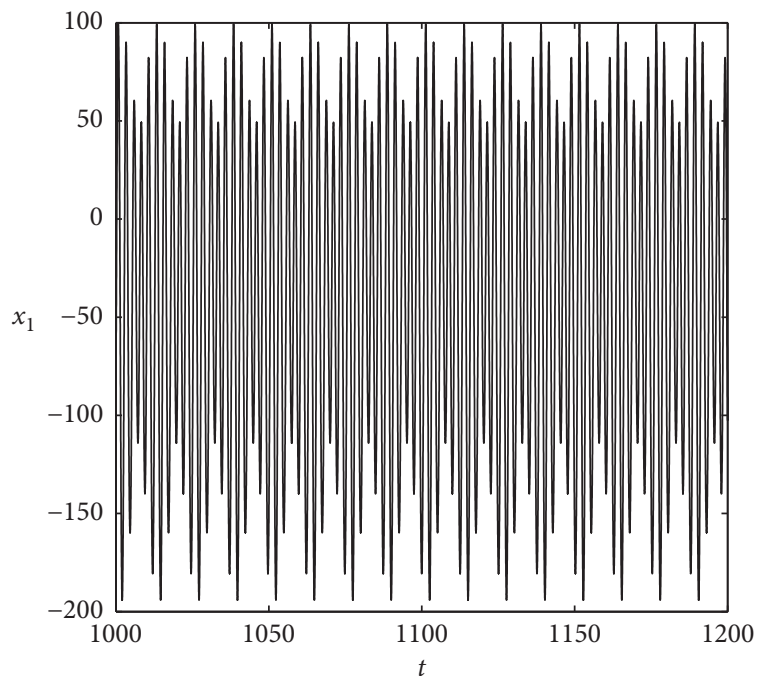

(a)

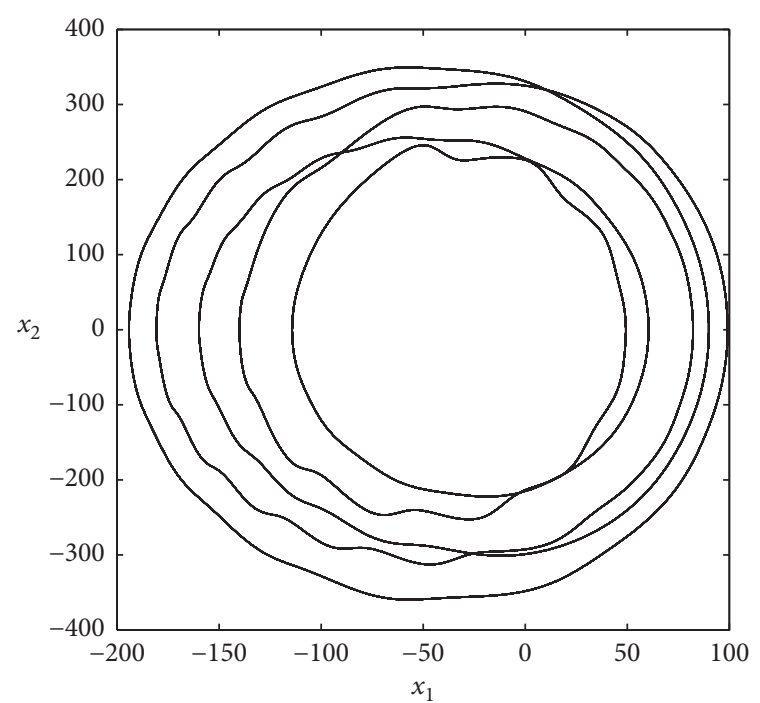

(c)

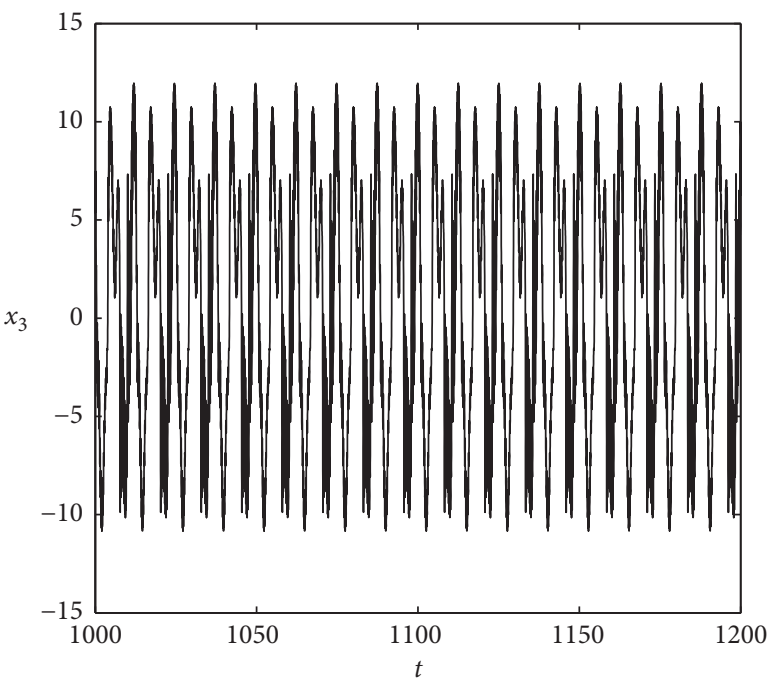

(b)

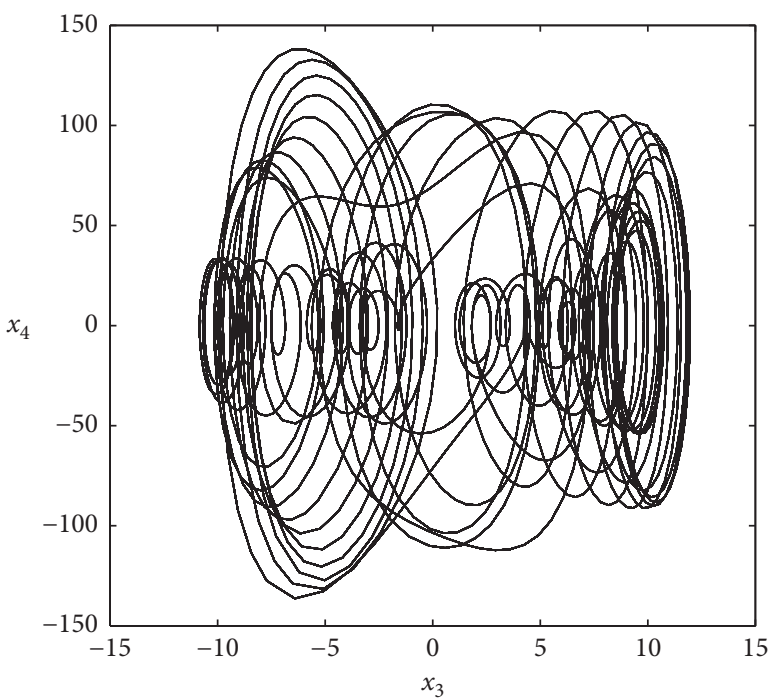

(d)

Figure 14: Continued. 


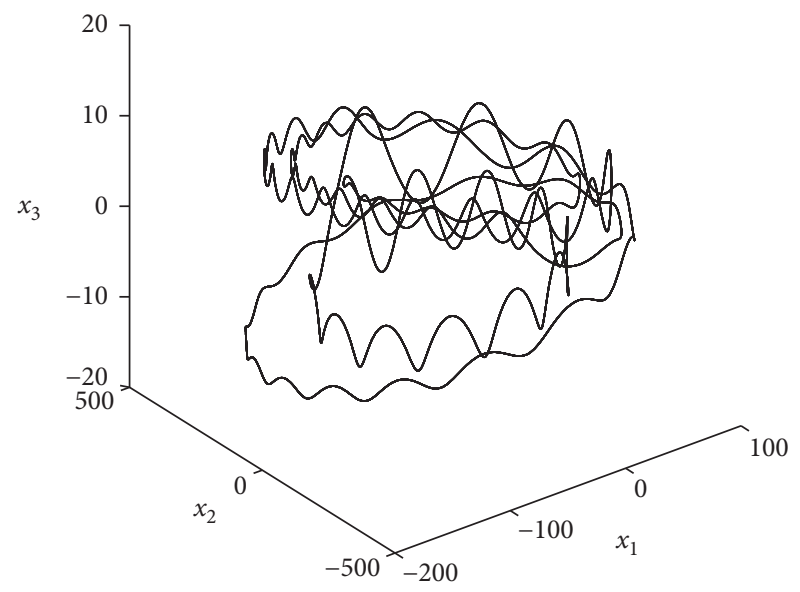

(e)

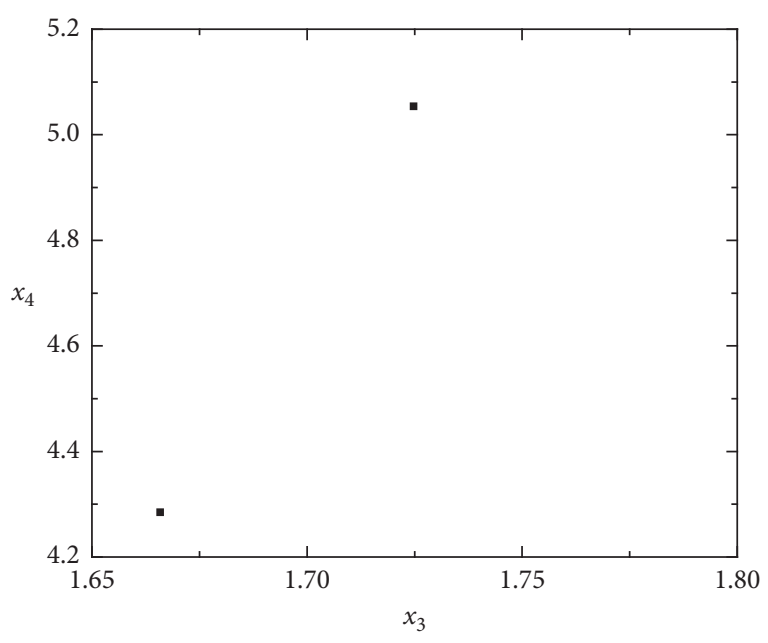

(f)

Figure 14: Periodic motion of the composite shell. (a) Waveform in the plane $\left(t, x_{1}\right)$. (b) Waveform in the plane $\left(t, x_{3}\right)$. (c) Twodimensional phase portrait in the plane $\left(x_{1}, x_{2}\right)$. (d) Two-dimensional phase portrait in the plane $\left(x_{3}, x_{4}\right)$. (e) Three-dimensional phase portrait in the plane $\left(x_{1}, x_{2}, x_{3}\right)$. (f) Poincare diagram.

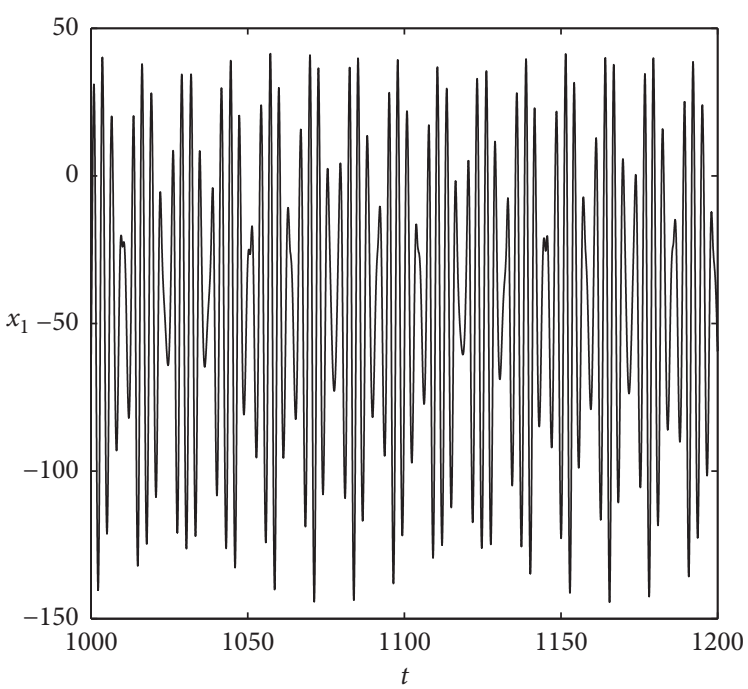

(a)

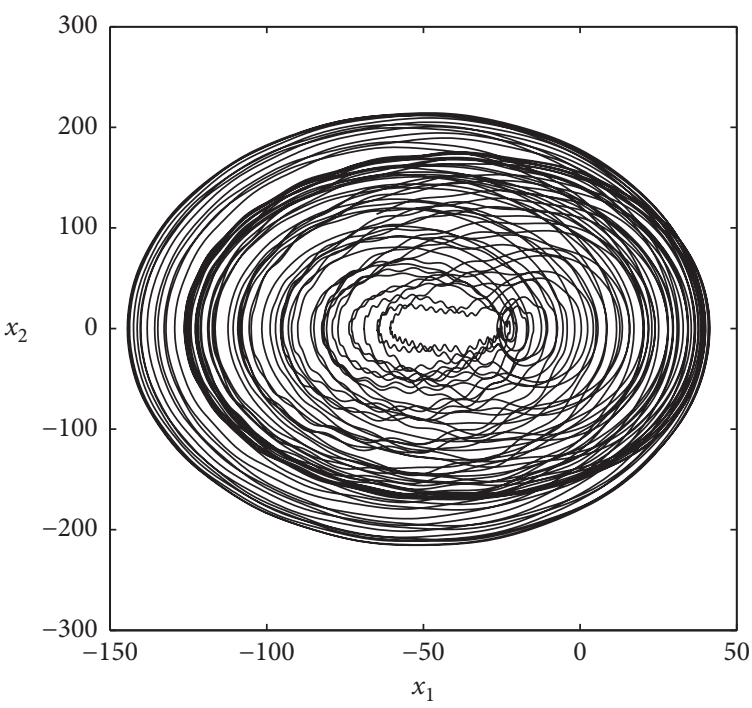

(c)

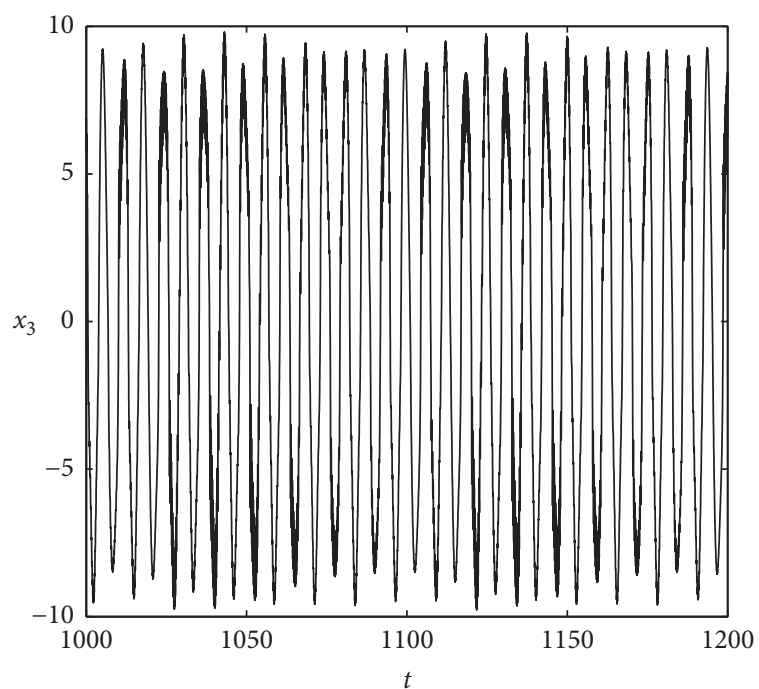

(b)

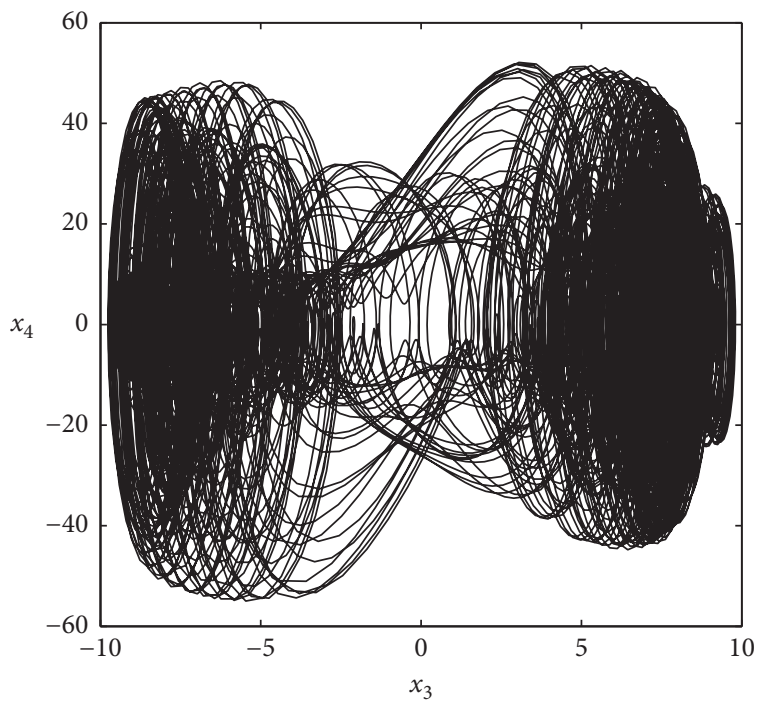

(d)

Figure 15: Continued. 


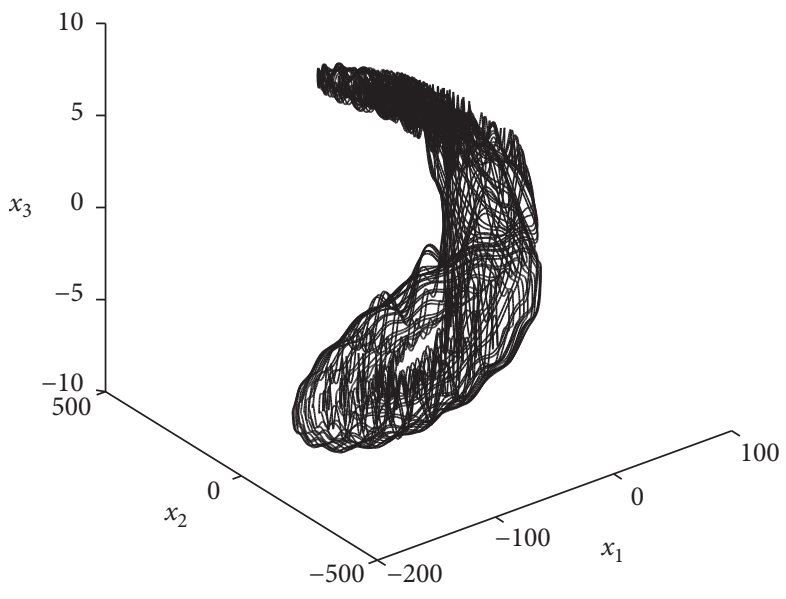

(e)

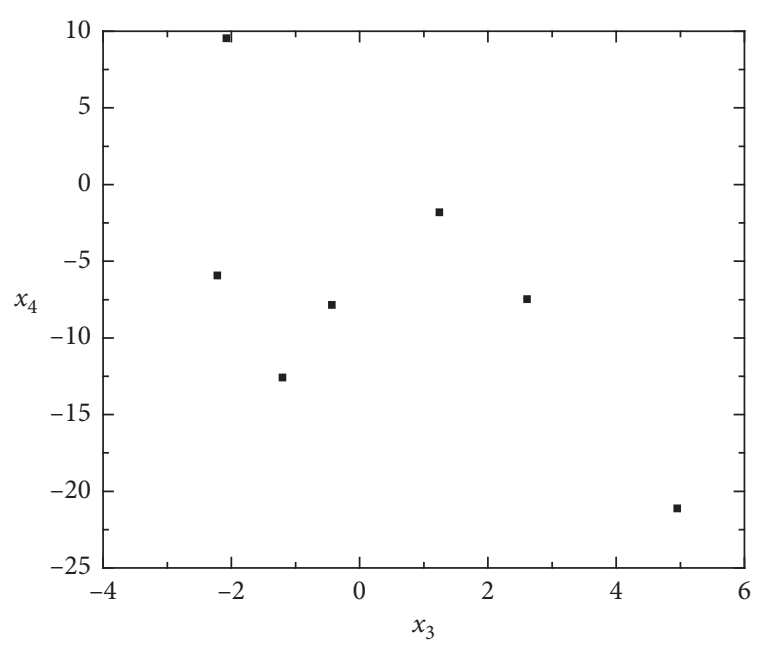

(f)

Figure 15: Chaotic motion of the composite shell when $f$ increases to 270. (a) Waveform in the plane $\left(t, x_{1}\right)$. (b) Waveform in the plane $\left(t, x_{3}\right)$. (c) Two-dimensional phase portrait in the plane $\left(x_{1}, x_{2}\right)$. (d) Two-dimensional phase portrait in the plane $\left(x_{3}, x_{4}\right)$. (e) Threedimensional phase portrait in the plane $\left(x_{1}, x_{2}, x_{3}\right)$. (f) Poincare diagram.

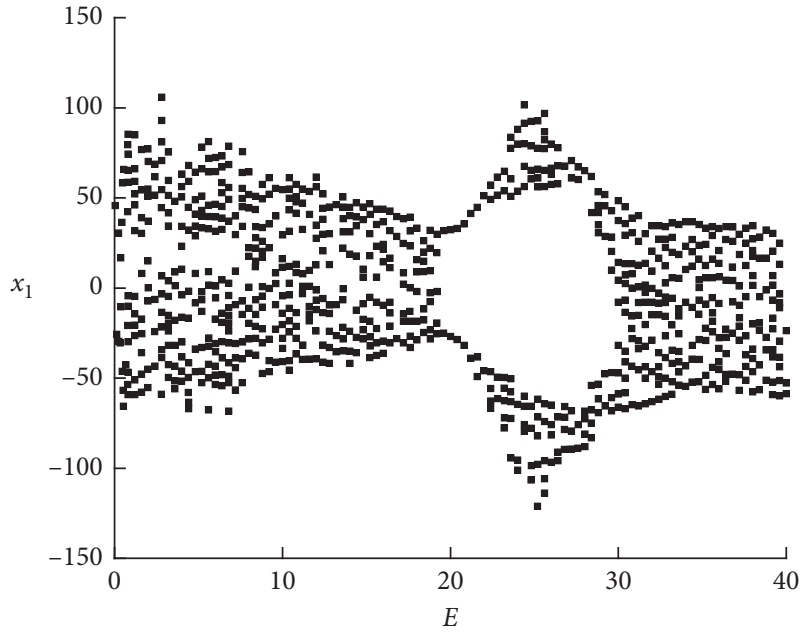

(a)

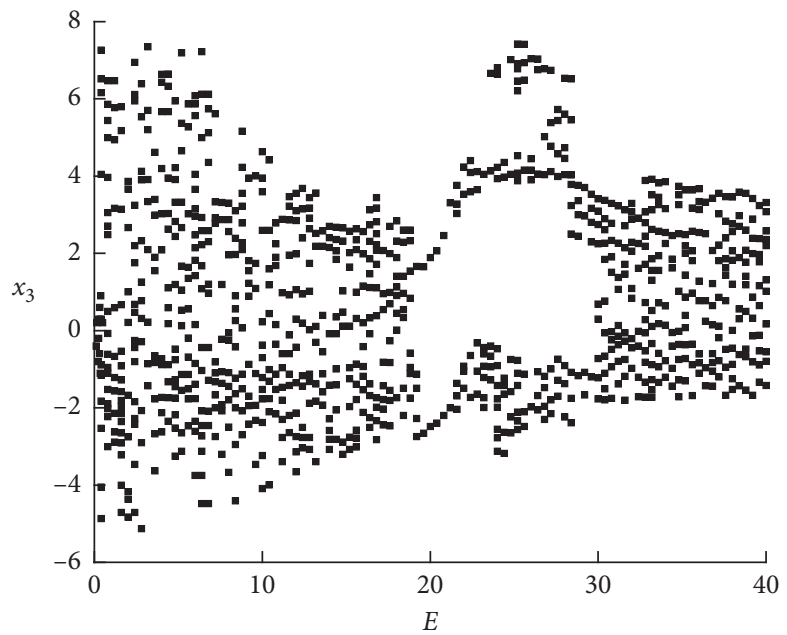

(b)

Figure 16: Bifurcation diagram of the composite shell with the electric field increase. (a) $x_{1}-E$. (b) $x_{3}-E$.

two-dimensional phase portraits in the planes $\left(x_{1}, x_{2}\right)$ and $\left(x_{3}, x_{4}\right)$. Figures 13(e), 14(e), and 15(e) show the threedimensional phase portraits in the space $\left(x_{1}, x_{2}, x_{3}\right)$, while Figures 13(f), 14(f), and 15(f) present the Poincare diagram. Figure 13 shows a group of characteristics of the chaotic motion for the system when $f$ equals 100. It also indicates that there exists energy transform between the responses of the shell in two different directions in Figure 13(e), which is caused by the nonlinear coupled terms of equations (20a) and (20b).

The periodic $n$ motions of the system are shown in Figure 14 when $f$ increases to 205 , and the phenomenon of energy transition between two modes of the shell also exists in Figure 14(e).

Then, when the aerodynamic disturbance force increases to 270 , the system enters into chaos, and the specific shape of the response is shown in Figure 15, which is similar to the chaotic motion in Figure 13.

From the above analysis, it can be seen that the aerodynamic force plays a key role in the dynamic behavior of the structure. Then, the piezoelectric parameters are used to adjust the nonlinear responses of the system. Fixing the above parameters and letting the aerodynamic disturbance force $f=270$, the bifurcation diagrams of Poincare sections are obtained in the $x$ and $z$ directions for the displacements of the middle surface of the shell when the electric field $E$ increases from 0 to 40 in Figure 16. It is found that the motion of the system can be adjusted from chaos to the period when $E$ is close to 20 , and when the value of $E$ is continuously increased, the system returns back to chaotic motion again.

From the above results of the numerical simulation, it is indicted that the piezoelectric parameters could adjust the 
vibration responses of the structure effectively. The electric field can change the piezoelectric performance of the shell through varying the stiffness of the structure, and the resonance of the shell would be restrained.

\section{Conclusion}

Considering the large geometrical deformation and piezoelectric material properties of the shell, nonlinear dynamic behaviors of a cantilever $d 33$ MFC shell are investigated. The aerodynamical force and the electric field are introduced and calculated. Then, the Galerkin method is employed to transform the partial differential equations into two nonlinear ordinary differential equations. Next, the influence of the electric field, external excitation force, and nonlinear parameters on the stability of the system is analyzed under $1: 1$ internal resonance. Furthermore, the effects of the material parameters on the deflection are discussed, and the complex nonlinear vibration responses of the MFC shell are simulated, including the periodic and chaotic motions.

This paper innovatively analyses the coupled vibration in two directions and points out that the energy transition exists between two coupled vibration directions. It is also revealed that the electric field of the MFC shell could adjust the dynamic stability of the structure from unstable to stable which would be an effective way to control responses for MFC structures. This research work may provide a way to use the MFC material in designing the wings of UAVs in the engineering field. The dynamic behavior of the wing in subsonic air flow conditions can be controlled by adjusting the electric field when the wing is made of the MFC material. Therefore, it could ensure the stability of the wing movement and the flight safety of the UAV.

\section{Data Availability}

The data used to support the findings of this study are available from the corresponding author upon request.

\section{Conflicts of Interest}

The authors declare that they have no conflicts of interest.

\section{Acknowledgments}

The authors gratefully acknowledge the support of the National Natural Science Foundation of China (NNSFC) through grant nos. 11572006, 11772010, and 11672008 and the Funding Project for Academic Human Resources Development in Institutions of Higher Learning under the Jurisdiction of Beijing Municipality (PHRIHLB).

\section{References}

[1] P. Tan, L. Tong, and D. Sun, "Dynamic characteristics of a beam system with active piezoelectric fiber reinforced composite layers," Composites Part B: Engineering, vol. 33, no. 7, pp. 545-555, 2002.

[2] S. C. Choi, J. S. Park, and J. H. Kim, "Vibration control of pretwisted rotating composite thin-walled beams with piezoelectric fiber composites," Journal of Sound and Vibration, vol. 300, no. 1-2, pp. 176-196, 2007.

[3] R. Schmidt and T. D. Vu, "Nonlinear dynamic FE simulation of smart piezolaminated structures based on first- and thirdorder transverse shear deformation theory," Advanced Materials Research, vol. 79-82, pp. 1313-1316, 2009.

[4] H. S. Kim, J. W. Sohn, and S.-B. Choi, "Vibration control of a cylindrical shell structure using Macro Fiber Composite actuators," Mechanics Based Design of Structures and Machines, vol. 39, no. 4, pp. 491-506, 2011.

[5] G. Shankar, S. K. Kumar, and P. K. Mahato, "Vibration analysis and control of smart composite plates with delamination and under hygrothermal environment," ThinWalled Structures, vol. 116, pp. 53-68, 2017.

[6] J.-S. Park and J.-H. Kim, "Analytical development of single crystal Macro Fiber Composite actuators for active twist rotor blades," Smart Materials and Structures, vol. 14, no. 4, pp. 745-753, 2005.

[7] O. Bilgen, A. Erturk, and D. J. Inman, "Analytical and experimental characterization of macro-fiber composite actuated thin clamped-free unimorph benders," Journal of Vibration and Acoustics, vol. 132, no. 5, article 051005, 2010.

[8] A. C. Cook and S. S. Vel, "Multiscale analysis of laminated plates with integrated piezoelectric fiber composite actuators," Composite Structures, vol. 94, no. 2, pp. 322-336, 2012.

[9] A. C. Cook and S. S. Vel, "Multiscale thermopiezoelectric analysis of laminated plates with integrated piezoelectric fiber composites," European Journal of Mechanics-A/Solids, vol. 40, no. 1, pp. 11-33, 2013.

[10] S. Kapuria and P. C. Dumir, "Geometrically nonlinear axisymmetric response of thin circular plate under piezoelectric actuation," Communications in Nonlinear Science and $\mathrm{Nu}$ merical Simulation, vol. 10, no. 4, pp. 411-423, 2005.

[11] S. Panda and M. C. Ray, "Nonlinear finite element analysis of functionally graded plates integrated with patches of piezoelectric fiber reinforced composite," Finite Elements in Analysis and Design, vol. 44, no. 8, pp. 493-504, 2008.

[12] P. Dash and B. N. Singh, "Nonlinear free vibration of piezoelectric laminated composite plate," Finite Elements in Analysis and Design, vol. 45, no. 10, pp. 686-694, 2009.

[13] M. N. Rao and R. Schmidt, "Static and dynamic finite rotation FE-analysis of thin-walled structures with piezoelectric sensor and actuator patches or layers," Smart Mater Struct, vol. 23, no. 9, article 095006, 2014.

[14] R. B. Williams, D. J. Inman, and W. K. Wilkie, "Nonlinear response of the Macro Fiber Composite actuator to monotonically increasing excitation voltages," in ASME 2004 International Mechanical Engineering Congress and Exposition, pp. 49-54, ASME, New York, NY, USA, 2004.

[15] H. Y. Zhang and Y. P. Shen, "Three-dimensional analysis for rectangular 1-3 piezoelectric fiber-reinforced composite laminates with the interdigitated," Composites Part B: Engineering, vol. 37, no. 7-8, pp. 603-611, 2006.

[16] S. Belouettar, L. Azrar, E. M. Daya, V. Laptev, and M. PotierFerry, "Active control of nonlinear vibration of sandwich piezoelectric beams: a simplified approach," Computers \& Structures, vol. 86, no. 3-5, pp. 386-397, 2008.

[17] M. Rafiee, M. Mohammadi, B. S. Aragh, and H. Yaghoobi, "Nonlinear free and forced thermo-electro-aero-elastic vibration and dynamic response of piezoelectric functionally graded laminated composite shells," Composite Structures, vol. 103, pp. 188-196, 2013.

[18] S. M. Hosseini, H. Kalhori, A. Shooshtari, and S. N. Mahmoodi, "Analytical solution for nonlinear forced response of a 
viscoelastic piezoelectric cantilever beam resting on a nonlinear elastic foundation to an external harmonic excitation," Composites Part B: Engineering, vol. 67, pp. 464-471, 2014.

[19] S. Mareishi, M. Rafiee, X. Q. He, and K. M. Liew, "Nonlinear free vibration, postbuckling and nonlinear static deflection of piezoelectric fiber-reinforced laminated composite beams," Composites Part B: Engineering, vol. 59, pp. 123-132, 2014.

[20] M. Rafiee, X. F. Liu, X. Q. He, and S. Kitipornchai, "Geometrically nonlinear free vibration of shear deformable piezoelectric carbon nanotube/fiber/polymer multiscale laminated composite plates," Journal of Sound and Vibration, vol. 333, no. 14, pp. 3236-3251, 2014.

[21] D. G. Ninh and D. H. Bich, "Characteristics of nonlinear vibration of nanocomposite cylindrical shells with piezoelectric actuators under thermo-mechanical loads," Aerospace Science and Technology, vol. 77, pp. 595-609, 2018.

[22] S. F. Lu, W. Zhang, and X. J. Song, "Time-varying nonlinear dynamics of a deploying piezoelectric laminated composite plate under aerodynamic force," Acta Mechanica Sinica, vol. 34 , no. 2 , pp. 87-98, 2018.

[23] J. A. Mitchell and J. N. Reddy, "A refined hybrid plate theory for composite laminates with piezoelectric laminae," International Journal of Solids and Structures, vol. 32, no. 16, pp. 2345-2367, 1995.

[24] S. Kapuria, "An efficient coupled theory for multilayered beams with embedded piezoelectric sensory and active layers," International Journal of Solids and Structures, vol. 38, no. 50-51, pp. 9179-9199, 2001.

[25] R. C. Batra and S. Vidoli, "Higher-order piezoelectric plate theory derived from a three-dimensional variational principle," AIAA Journal, vol. 40, no. 1, pp. 91-104, 2002.

[26] S. Lentzen and R. A. Schmidt, "Geometrically nonlinear finite element for transient analysis of piezolaminated shells," ThinWalled Structures, 2005.

[27] S. S. Prasath and A. Arockiarajan, "Effect of interphase and thermal environment on the effective properties of MacroFiber Composites (MFC)," Composites Part B, vol. 75, pp. 327-335, 2015.

[28] S. S. Prasath and A. Arockiarajan, "Experimental and theoretical investigation on the thermo-electro-elastic properties of Macro-Fiber Composites (MFC)," Composite Structures, vol. 122, pp. 8-22, 2015.

[29] S. Q. Zhang, Y. X. Li, and R. Schmidt, "Modeling and Simulation of macro-fiber composite layered smart structures," Composite Structures, vol. 126, pp. 89-100, 2015.

[30] M. A. Kouchakzadeh, M. Rasekh, and H. Haddadpour, "Panel flutter analysis of general laminated composite plates," Composite Structures, vol. 92, no. 12, pp. 2906-2915, 2010.

[31] F.-M. Li, Z.-B. Chen, and D.-Q. Cao, "Improving the aeroelastic flutter characteristics of supersonic beams using piezoelectric material," Journal of Intelligent Material Systems and Structures, vol. 22, no. 7, pp. 615-629, 2011.

[32] S.-Y. Kuo, "Flutter of rectangular composite plates with variable fiber pacing," Composite Structures, vol. 93, no. 10, pp. 2533-2540, 2011.

[33] S. Y. Kuo, "Thermal buckling, vibration and flutter of composite laminates containing two non-uniformly distributed," Journal of Aeronautics, Astronautics and Aviation, vol. 48, no. 3, pp. 173-182, 2016.

[34] W. Zhang, L.-L. Chen, X.-Y. Guo, and L. Sun, "Nonlinear dynamical behaviors of deploying wings in subsonic air flow," Journal of Fluids and Structures, vol. 74, pp. 340-355, 2017. 


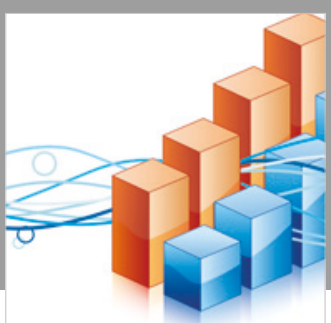

Advances in

Operations Research

\section{-n-m}
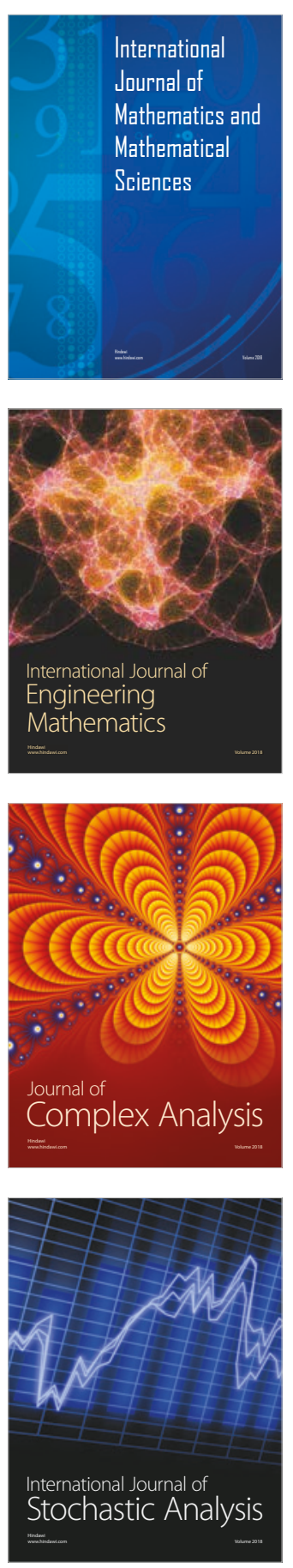
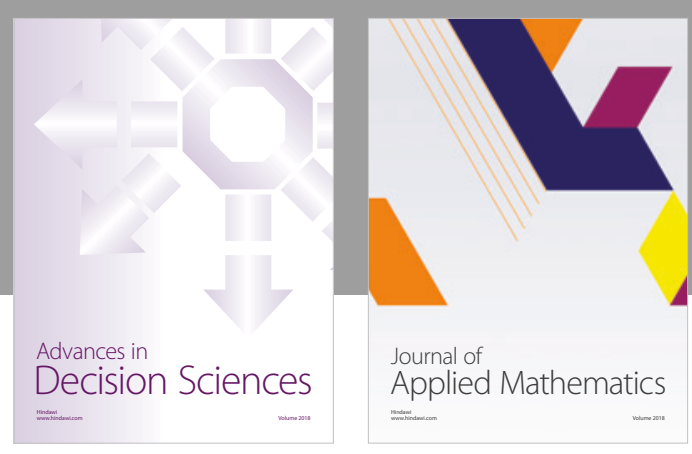

Journal of

Applied Mathematics
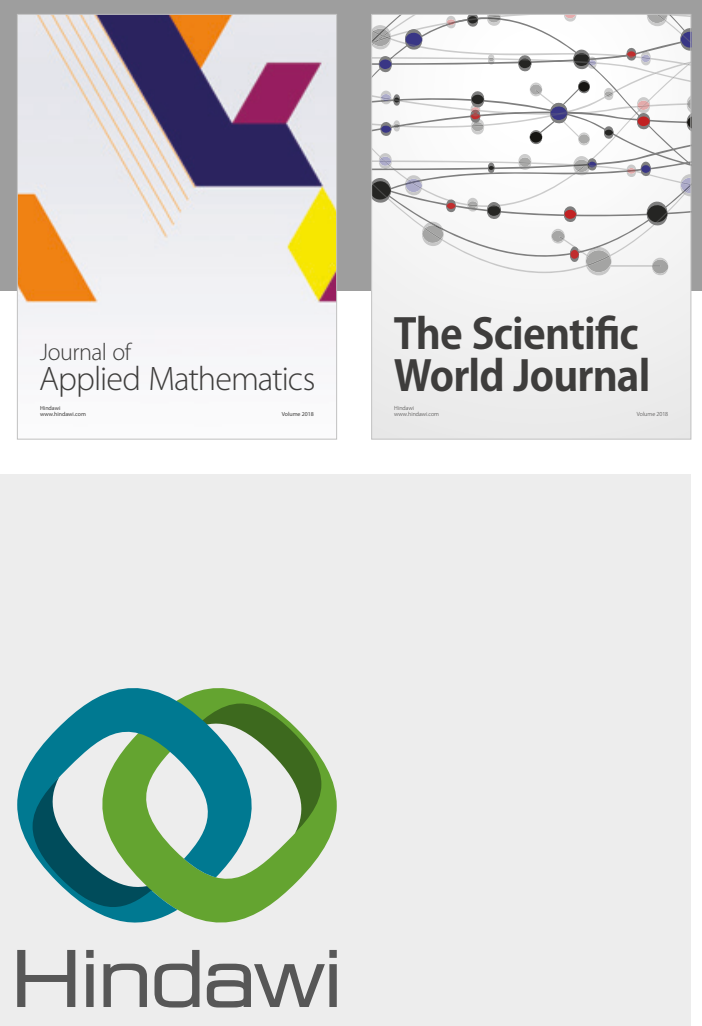

Submit your manuscripts at

www.hindawi.com

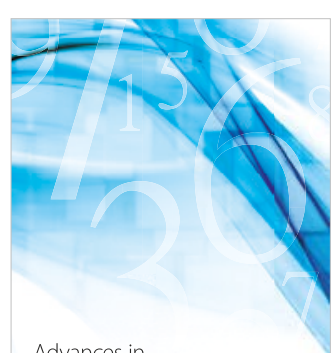

Advances in
Numerical Analysis
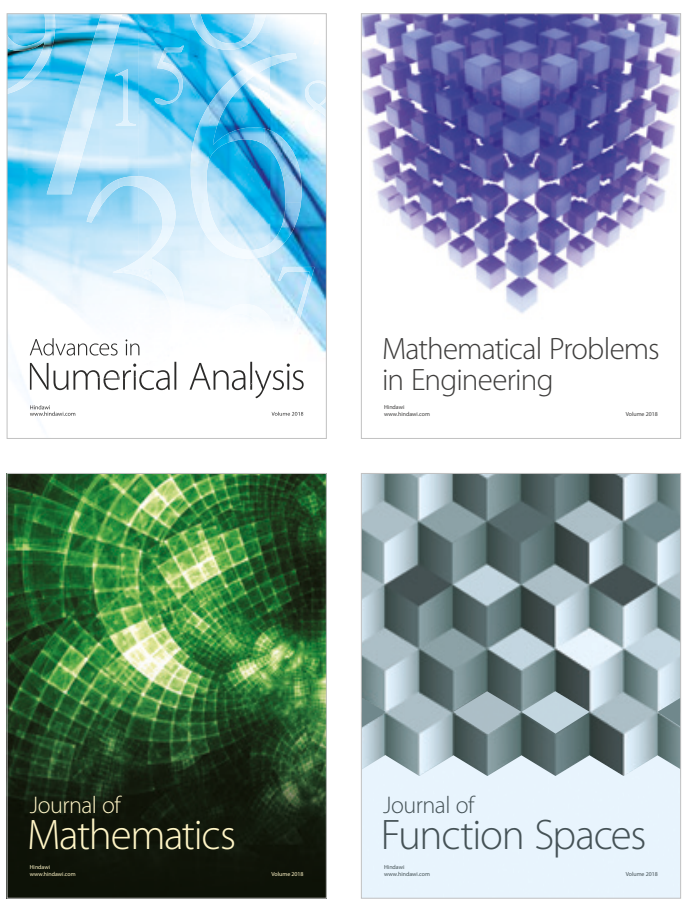

Mathematical Problems in Engineering

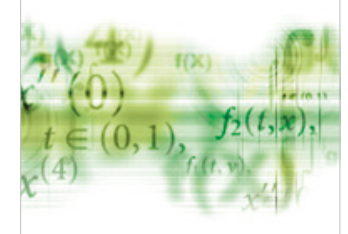

International Journal of

Differential Equations

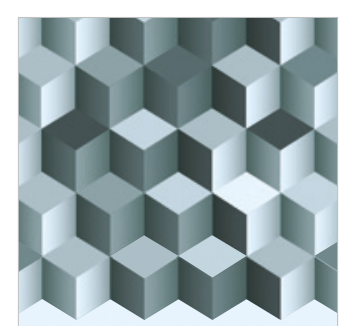

Journal of

Function Spaces
The Scientific

World Journal

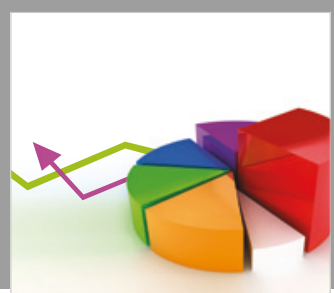

Journal of

Probability and Statistics
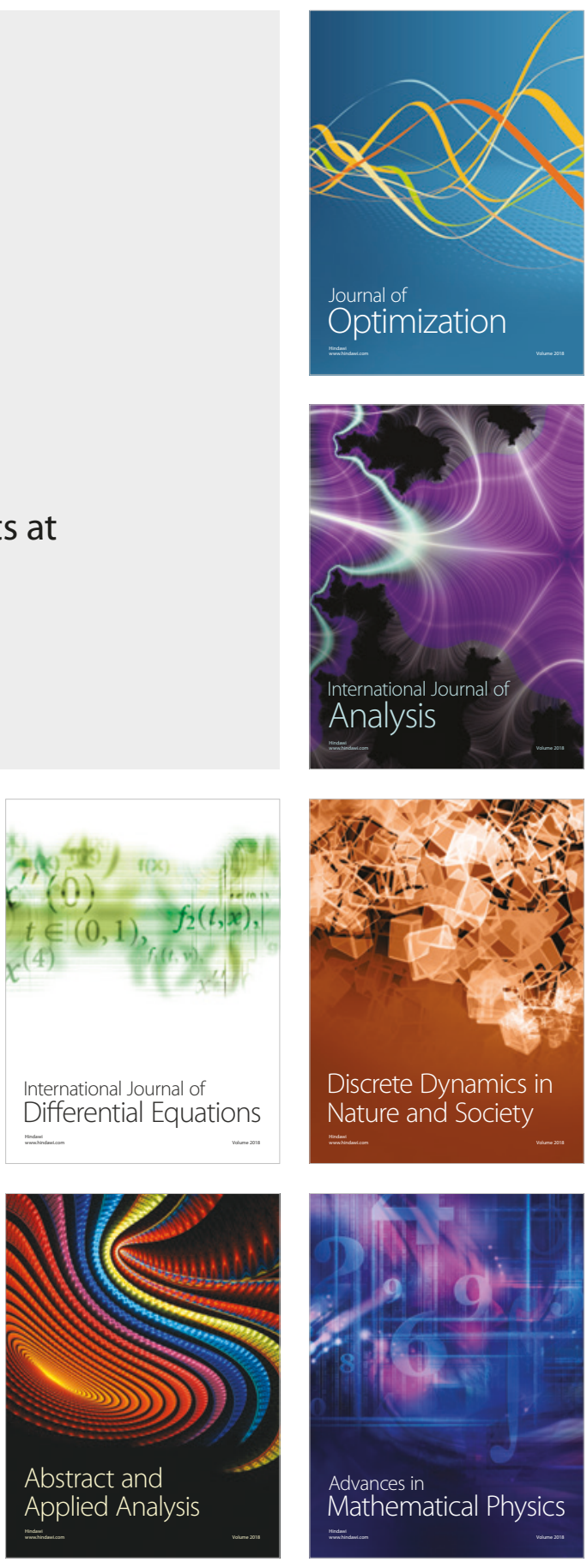